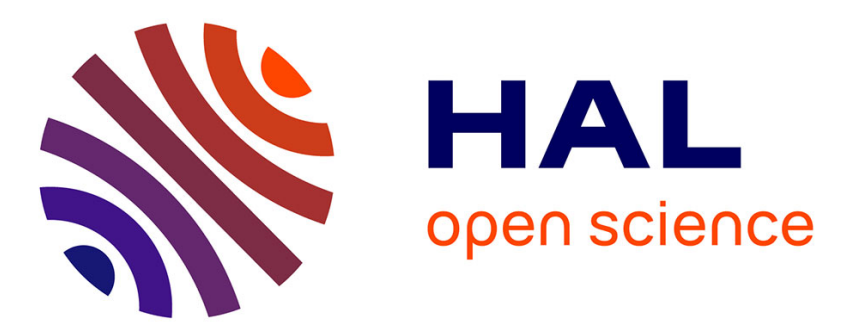

\title{
Combining Monte Carlo Simulations and Options to Manage the Risk of Real Estate Portfolios
}

Charles-Olivier Amédée-Manesme, Michel Baroni, Fabrice Barthélémy, Etienne Dupuy

\section{- To cite this version:}

Charles-Olivier Amédée-Manesme, Michel Baroni, Fabrice Barthélémy, Etienne Dupuy. Combining Monte Carlo Simulations and Options to Manage the Risk of Real Estate Portfolios. 2011, pp.31. hal-00671067

\section{HAL Id: hal-00671067 https://essec.hal.science/hal-00671067}

Submitted on 16 Feb 2012

HAL is a multi-disciplinary open access archive for the deposit and dissemination of scientific research documents, whether they are published or not. The documents may come from teaching and research institutions in France or abroad, or from public or private research centers.
L'archive ouverte pluridisciplinaire HAL, est destinée au dépôt et à la diffusion de documents scientifiques de niveau recherche, publiés ou non, émanant des établissements d'enseignement et de recherche français ou étrangers, des laboratoires publics ou privés. 


\section{Combining Monte Carlo Simulations}

and Options to Manage the Risk of Real

\section{Estate Portfolios}

Research Center

ESSEC Working Paper 1115

2011

Charles-Olivier Amédée-Manesme

Michel Baroni

Fabrice Barthélémy

Etienne Dupuy 


\title{
Combining Monte Carlo Simulations and Options to Manage the Risk of Real Estate Portfolios
}

\author{
Charles-Olivier Amédée-Manesme \\ THEMA, Université de Cergy-Pontoise, 33, Bd du Port, 95011, Cergy-Pontoise Cedex, France. \\ BNP-PARIBAS REAL ESTATE INVESTMENT SERVICES, 13 boulevard du Fort-de-Vaux, 75017 Paris, France. \\ Tel: (33) 6641647 25. Email: charleso.amedeemanesme@gmail.com \\ Michel Baroni \\ ESSEC Business School, Avenue Bernard Hirsch - B.P. 105, 95021, Cergy-Pontoise Cedex, France. \\ Tel: (33) 1344330 92. Email: baroni@essec.edu \\ Fabrice Barthélémy \\ THEMA, Université de Cergy-Pontoise, 33, Bd du Port, 95011, Cergy-Pontoise Cedex, France. \\ Tel: (33) 1342562 53. Email: fabrice.Barthélémy@eco.u-cergy.fr \\ Etienne Dupuy \\ BNP-PARIBAS REAL ESTATE INVESTMENT SERVICES, 13 boulevard du Fort-de-Vaux, 75017 Paris, France. \\ Tel: (33) 1556525 99. Email: etienne.dupuy@bnpparibas.com
}

\begin{abstract}
This paper should not be reported as representing the views of the BNP Paribas group ("BNP Paribas") or its subsidiary BNP Paribas Real Estate ("BNP Paribas"). The views expressed in this paper are those of the authors and do not necessarily represent those of BNP Paribas or BNP Paribas policy. Papers describe research in progress by the authors and are published to elicit comments and to further debate.
\end{abstract}

\begin{abstract}
This paper aims to show that the accuracy of real estate portfolio valuations can be improved through the simultaneous use of Monte Carlo simulations and options theory. Our method considers the options embedded in Continental European lease contracts drawn up with tenants who may move before the end of the contract. We combine Monte Carlo simulations for both market prices and rental values with an optional model that takes into account a rational tenant's behavior. We analyze to what extent the options exercised by the tenant significantly affect the owner's income. Our main findings are that simulated cash flows which take account of such options are more reliable that those usually computed by the traditional method of discounted cash flow. Moreover, this approach provides interesting metrics, such as the distribution of cash flows. The originality of this research lies in the possibility of taking the structure of the lease into account. In practice this model could be used by professionals to improve the relevance of their valuations: the output as a distribution of outcomes should be of interest to investors. However, some limitations are inherent to our model: these include the assumption of the rationality of tenant's decisions, and the difficulty of calibrating the model, given the lack of data.

After a brief literature review of simulation methods used for real estate valuation, the paper describes the suggested simulation model, its main assumptions, and the incorporation of tenant's decisions regarding break options influencing the cash flows. Finally, using an empirical example, we analyze the sensitivity of the model to various parameters, test its robustness and note some limitations.
\end{abstract}

KEYWORDS: Monte Carlo Simulations; Real Estate Portfolio Valuation; Break options; Lease Structure; Options 


\section{Introduction}

Since real estate assets transactions are relatively infrequent there is a lack of existing market valuations by means of which value might be estimated. Real estate portfolios are mostly evaluated using valuation models. Investors have to add their own perception of risk to these models to arrive at a decision to buy or to sell an asset. Usually the main financial risks they face relate to operating costs, vacancy rates, lease contracts and liquidity. The principal opportunities to improve performance may arise from operating costs, terminal value and rental income growth (leases often provide mechanisms to increase total payments over the course of the lease). The need for appraisal in the real estate business arises from the heterogeneous nature of properties: all properties differ from each other in their location at least - and this is one of the most important determinants of their value. A centralized Walrasian price cannot therefore be set for trading property assets, as happens for securities in capital markets. The absence of a market-based pricing mechanism prompts the need to improve valuation methods; in particular, to better reflect the risks involved in real estate.

Real estate valuation includes the appraisal of the prospective price of a property. Real estate can involve almost all of the pathologies encountered in the practice of valuation, although traditionally considered to be a more predictable asset type. Following Nassim Taleb, who in his foreword to Geman (2005) emphasized the specific nature of commodities, we emphasize in this introduction some of the specificities of real estate assets. The first specific characteristic is a unique location. While a security is an abstract item, having no location and existing as a simple balance sheet entry, properties present locational characteristics that make arbitrage arduous and comparison difficult. Secondly, there is a temporal dimension: a real estate asset is illiquid. The action of buying and selling is quite predictable in real estate, being rooted in its physical nature. Buying and selling spans a matter of months for real estate assets, compared with a security which can be traded twice in less than a second. Thirdly, there is the matter of the size of the investment: real estate assets are large, indivisible assets. Fourthly, the obsolescence rate: a building doesn't keep its level of efficiency over the time. Fifth is the incidence of cash flow: small cash flows occur during the period during which the asset is held, and large flows occur at the time of sale. Taking all these hurdles into account, the difficulties of real estate valuation become more obvious.

The major traditional valuation methods, widely accepted by practitioners and academics, are: construction cost, comparables, yield capitalization, discounted cash-flow, or the asset's present value. However these traditional valuation methods suffer from numerous limitations. In particular, they all suffer at least from the same inherent disadvantage: they do not take proper account of risk, and they are too sensitive to some parameters, such as the infinite rate of growth of the cash flow. These limitations are discussed in Fama and French (1989), Ferson and Campbell (1991), Achour-Fischer (1999) and French and Gabrielli (2004), in addition to Myers (1974) who favors the asset present-value approach. Furthermore, the traditional valuation methods do not meet certain basic requirements, such as probability distribution, standard error calculation or confidence interval. Such limitations are really problematic; we propose in this paper to overcome all of these issues by suggesting a new valuation method which, using Monte Carlo simulations and options, incorporates uncertainty into the valuation process. The Monte Carlo method has long been applied to incorporate risk in simulating numerous scenarios. Adding an optional element to the cash flows also allows 
us to take account of the risk born by the lease contract. Moreover, methodology using simulations techniques enables us to derive a broad spectrum of applications and measurements calculations (such as Value at Risk).

The first use of simulation techniques for real estate appraisal can be found in Pyhrr (1973), who analyzes the risk of a real estate investment. Numerical methods are used, amongst others, by Cooper and Pyhrr (1973), Wofford (1978), Mollart (1988), Li (2000), Kelliher \& Mahoney (2000), Dupuy (2003, 2004), French \& Gabrielly (2004, 2005), Hoesli, Jani and Bender (2006) and Baroni, Barthélémy \& Mokrane (2007a, 2007b). The idea initiated by Pyhrr (1973) involves making risk assessment more explicit, and making better use of modern financial theory and computer resources. In 1973 Pyhrr underlined especially how it is possible to use numerical methods to develop models that assist the investment decision maker to take into account three dimensions: the degree of uncertainty, time dependence and complexity. This model forms the basis of all the modern models that use Monte Carlo simulation for real estate.

This paper builds principally on three sources: Hoesli, Jani and Bender (2006), Baroni, Barthélémy and Mokrane (2007a) and Dupuy (2003). So far as we are aware, these papers also represent the first practical use of Monte Carlo simulations.

Hoesli, Jani and Bender in 2006 seek to add uncertainty to the valuation process and solve the hypothesis of constant weighted average cost of capital by using Monte Carlo simulations. In particular, they simulate the risk-free rate by using the Cox, Ingersoll, Ross (1989) dynamic model, and incorporate variations in the risk-free interest rate. Moreover, the model proposed by the authors supports the addition of some building-specific characteristics into the risk premium. This is achieved by rating the states of the markets and assessing property-specific hedonic characteristics, which are then translated into a building-specific risk premium. This approach is very similar to the scoring method used by the hedge funds industry. The proposed approach succeeds in overcoming some of the worst limitations of the discounted cash flow model, and also incorporates risk into the cash flows using a time-varying weighted average cost of capital. The essential contribution of this method is that it does not require prior knowledge of the asset's value (usually necessary to determine the weighted average cost of capital).

In 2007, Baroni, Barthélémy and Mokrane (2007a) proposed a new real estate portfolio valuation methodology that uses Monte Carlo simulations. They proposed simulating both the rental value and the price of the asset. Their model is innovative by virtue of its introduction of uncertainty not only into cash flows, but also into the price of the asset. Furthermore, they model the vacancy rate using a uniform law, and thus also incorporate the possibility of vacancy changes in the portfolio. Their article allows, among other things, one of the most profound issues in valuation to be overcome: the terminal value calculation is simulated rather than being dependent on a dubiously infinite growth rate. Empirical tests using an index constructed in Baroni, Barthélémy and Mokrane (2005) prove how robust their methodology is by comparison with the traditional discounted cash flow approach. Likewise this approach allows the measurement of the risk given the distribution of outcomes. In particular, the value at risk can easily be computed. This paper also opens the way to numerous applications in portfolio management; for instance Baroni, Barthélémy and Mokrane (2007b) or Barthélémy and Prigent (2009) derive the optimal holding period for a portfolio, a well-known issue in Finance. 
Dupuy first introduced the combination of Monte Carlo simulations with options for real estate valuation in 2003. He considers the risk born by the real estate owner, focusing on the options granted to the tenant in a lease contract. Dupuy concentrates on market rental values, and combines Monte Carlo simulations for these market rental values combined with options to demonstrate how a traditional lease structure transforms normally distributed market rental values into a reduced set of income paths. More precisely, the author derives tenant behavior by comparing expectations of tenant cash flows and market rental value cash flows for each simulated scenario. In addition, Dupuy derives many applications and measurements regarding the average amount of time in premises, or the probabilities of a tenant vacating. This is not however incorporated in the price of the asset at the end of the period.

Following Dupuy (2003) and Baroni, Barthélémy and Mokrane (2007a), we undertake in this paper to improve existing commercial real estate valuation methodologies by introducing uncertainty and risk into the valuation process. We achieve this by combining Monte Carlo simulations with option theory.

Let us first focus upon one of the most essential determinants of the commercial lease contract: the lease structure. In Europe, lease structures vary from one country to another, and are even more different in the UK in comparison with continental Europe. Information on the lease structure is thus an essential component of any proper cash-flow model. Basically a lease is a rental agreement between a landlord and a tenant. The lease provides detailed information about expected cash flows for years to come. In particular, the lease usually specifies starting date, initial rent, expiry date of the lease, indexation rules, and options available to the tenant to leave the premises before the expiry of the lease. These last options are called the break (or sometimes renewal) options. They are a particular feature of the continental Europe lease, and one of the greatest risks faced by European real estate investors. A break option is an asymmetric right in favor of the tenant; i.e. at the time of a break option, the tenant has the right, but not the obligation, to terminate the lease. A tenant may well leave at the time of a break option; therefore break options are likely to cause vacancy, to incur a hiatus in cash flows, and this therefore represents the principal cash flows risk faced by investors. Obviously a vacant space incurs costs but no revenue. In addition, such premises may become outdated or more quickly obsolete, and thus also involves an increased risk of capital loss.

The proposed model takes into account the risk underlying the lease structure in relation to the level of market rental values, possible agency costs and the current rent paid in the portfolio as a whole. We use both Monte Carlo methodology and apply basic option theory:

- We make use of Monte Carlo simulations for pricing the portfolio, and for all the market rental values of all the rental spaces in the portfolio;

- We apply basic option theory to the break options granted to the tenant.

In consequence each Monte Carlo scenario confers a value on each lease. This is achieved through three factors: the simulated state of the market rental value, the lease structure and the tenant's decision (all this according to its current rent and assuming rational behavior). Therefore the model incorporates uncertainty concerning the level of cash-flows according to the state of the market rental values, but also into the price component. We claim that this method is more accurate and more reliable than traditional methods. 
Having briefly discussed real estate valuation methods and their limitations, and having presented the existing literature on simulations methods used in real estate valuation, we develop our model in the following section. In particular, in this second section, we focus on the risks that must be taken into account, among which risks is the risk of vacancy, which we model with options. In the third section we describe and illustrate simulations applied to one lease contract. The fourth section provides applications and illustrations of our model based on a case study in which we conduct a sensitivity analysis to measure the robustness of our model. Section 5 summarizes the main conclusions. ${ }^{1}$

\section{The basic model}

Our model is based on the non-deterministic (stochastic) approach taken by the classical discounted cash flow method ${ }^{\mathrm{i}}$. Our objective is therefore to determine, as accurately as possible, all the future cash flows generated by the portfolio. Integrating the risk in each cash flow enables us to compute the global risk of a real estate portfolio. In particular, our approach takes into account the tenant's behavior in respect of the specific lease structure of the portfolio in commercial real estate. The model estimates both the risk included in the cash flows generated by the assets of the portfolio, and the risk for their prices.

To describe more precisely these risks we consider five main sources of risks:

- the indexation risk of the rental value (i);

- the evolution of market rental value prices (ii);

- the potential vacancy rate of the portfolio (iii);

- the variation of expenses over time (iv);

- market price risk (v).

The conjunction of these various sources of risk enables us to decompose the risks related to the portfolio's cash flows. We first analyze cash inflows relative to rents, and then cash outflows, so that we might finally construct a valuation model for the portfolio.

Our model can take into account the specificity of each submarket and of each lease structure within the portfolio. It means that we will consider $n$ assets (or $n$ properties) to be invested in $m$ submarkets. We assume only $(m \leq n)$.

\subsection{Cash Inflows}

\footnotetext{
${ }^{1}$ Prerequisite: We state here some assumptions we make for all the paper and our terminology.

Throughout the paper, we assume that investors are rational and use the net present value to decide upon favorable investments. We also assume throughout the paper a real estate portfolio composed of many commercial properties. The properties are themselves composed of many spaces that can be rented. The portfolio is acquired or sold as a whole during one period (the properties which make up the portfolio are not gradually acquired over many periods). At the point of acquisition the spaces composing the portfolio can be let or not (if not, they are vacant). The space leased at the point of acquisition may have been contracted at different dates before the acquisition; therefore they have different break option dates and different maturity dates. For the purpose of simplification we will consider that all the leases already contracted, or that may be contracted, have been signed, or will be signed, on the $1^{\text {st }}$ of January: all the cash flows occur on the $1^{\text {st }}$ of January (we do not consider quarterly payment). In our model and simulation, a 9-year lease contract that begins at the 1st period will have its first payment during the $1^{\text {st }}$ period and the last payment during the $9^{\text {th }}$ period. A lease contract that has its first break option at year 3 may only be vacant during the $4^{\text {th }}$ period; thereby it produces at least three cash inflows. The paper therefore makes the implicit assumption that rents are paid one period after acquisition or signature of a lease-contract: the rents decided at time $t$ are received one period after at time $t+1$.
} 
The cash flows generated by a real estate investment are principally composed of rental payments. In order to compute future rents, three major factors have to be considered:

- the evolution of rents over time, or the way that rents are revised in lease contracts (i);

- the evolution of market rental value for the submarket corresponding to the asset (ii);

- the evolution of possible vacancies for each lease (iii).

$\forall i=1, \ldots, n$, let us define $S_{i}$ as the subset of the dates where the option to leave can be exercised for the space $i$. We analyze the rent for a given space $i$ belonging to a given submarket $j \in[1, m]$. Its rent at time $t(t=0, \cdots, T)$ is called Rent $t_{t, i}$, its corresponding market rental value is $M R V_{t, i}^{j}$, and the index (when applicable) mentioned in the lease contract for the rents revision $I_{t, j}^{\text {Rent }} t_{t, i}$.

The space may be let, or not. If it is let, the tenant has, or does not have, the possibility of leaving at a predetermined date during the term of the lease (the break option). When the lease terminates both tenant and landlord can each decide to either continue with the lease, or not (with some limitations which we consider irrelevant here). The end of the lease is therefore also a break option, but symmetrical, as both tenant and landlord can exercise it, even if often with different costs. Thus uncertainty regarding changes in the rent over time mainly arises from the possibilities that the break option will be exercised, ${ }^{2}$ and the length of any vacancy periods. This is precisely what we investigate in our model. We examine the risk presented by the break options and by the length of vacancy in terms of cash-flows and of the valuation of the portfolio. At a break option point a tenant has two possible choices: staying or leaving. From the owner's perspective this can be translated into continuity of cash flows versus a void period (or even a negative cash flow). Given the assumption of rational behavior, the model we construct is capable of determining the choices open to a tenant, incorporating their consequences in cash-flows. Faced with a break option, both tenant and landlord wish to increase their wealth. The landlord wants to hedge his revenues, and possibly increase the value of his building; the tenant wishes to minimize the current rent paid and his expenses related to the premises. Therefore, assuming rational behavior, when faced with a break option the tenant stays in the premises only if the rent currently paid is not too high in comparison with the current market rental value available for similar spaces on the market, plus relevant "transaction" costs ${ }^{\mathrm{ii}}$. Concerning the vacancy length, we choose to model it using a random discrete distribution: Poisson's law. In this way the prospects of a vacant space being let or remaining vacant are considered.

At each period there exist three possible outcomes of modeled Rent $_{t, i}$ :

a) If a lease has just been contracted, at period $t$, the lease is around the market price. Rent $_{t, i}=M R V_{t, i}^{j}+\varepsilon_{i}, \forall t \geq 0$, with $\mathrm{E}\left(\varepsilon_{i}\right)=0$ and $\mathrm{V}\left(\varepsilon_{i}\right)=\sigma_{i}^{2}$

2 - We do not consider the possibility of bankruptcy in our model even this risk remains a relevant one. 
The noise $\varepsilon_{i}$ arises mainly from market incompleteness and inefficiencies (indeed information on real estate transactions is never fully available).

b) For a current lease, the rent at period $t$ is:

$$
\operatorname{Rent}_{t, i}=f\left(\operatorname{Rent}_{t-1, i}, \Delta I_{t, j}^{\text {Rent }_{t, i}}\right), \forall t \geq 0, \forall i, \forall j,
$$

$I_{t, j}^{\text {Rent } t_{i, i}}$ represents the index to which the rent has been fixed from the beginning of the lease. This case remains valid even for the first period of the lease $(t=0)$; in this case, the lease has already been contracted at the time the portfolio is bought. Indeed the beginning of the analysis does not usually correspond to the beginning of the leases in the portfolio.

c) At period $t$, the premises may be vacant: in this case, no rent is paid:

$$
\text { Rent }_{t, i}=0, \forall t, \forall i
$$

Hence the model for the rent at period $t$ of the premises $i$ may be summarized as follows:

$$
\forall t, \forall i, \forall j, \text { Rent }_{t, i}=\left\{\begin{array}{l}
M R V_{t, i}^{j}+\varepsilon_{i}, \text { with } \mathrm{E}\left(\varepsilon_{i}\right)=0 \text { and } \mathrm{V}\left(\varepsilon_{i}\right)=\sigma_{i}^{2} \\
f\left(\operatorname{Rent}_{t-1, i}, \Delta I_{t, j}^{\text {Rent }_{t, i}}\right) \quad \text { (b) } \\
0 \quad \text { (c) }
\end{array}\right.
$$

The essential characteristic of each space is to be let or vacant at period $t$. The model focuses on the dynamics between two consecutive periods, for instance period $t$ and period $t+1$ :

(i) Does a let space remain let or not?

(ii) Does a vacant space remain vacant or not?

Determining the way a current or a potential tenant will behave is difficult. In our context, it means determining if a vacant space will attract a tenant, and if a let space will keep its tenant in the premises. The aim is to find a rule or a principle that can be used as a standard for the two predefined cases, (i) and (ii), that can rationally be used in the context of real estate portfolio management and real estate portfolio valuation. We propose two rules: one to decide if a let space remains let when facing a break option (i); the other to determine how long a vacant space stays vacant (ii).

(i) The first rule is based on a comparison between the current rent and the market rental value available for similar space in the same market. Under the assumption of rational behavior, the option to leave is exercised by the tenant only if it is the time of a possible break option $\left(t \in S_{i}\right)$ and if the rent currently paid is too high in comparison to the current market value ${ }^{3}$. Mathematically, this can be written as:

$$
\forall i=1, \ldots, n, \forall i=1, \ldots, m, \forall t \in S_{i} \text {, if } \frac{\text { Rent }_{t, i}}{M R V_{t, i}^{j}} \geq 1+\alpha \text {, then } \text { Rent }_{t+1, i}=0 \text {, for } \alpha>0 \text {. }
$$

\footnotetext{
3 - In practice, different events can occur. Landlords may concede a potential revision of the rental level in order to prevent void situation while, at the same time, tenants may prefer to stay in the premises in order to save transaction costs. Negotiations is therefore common.
} 
If there is no possible break option at period $t\left(t \notin S_{i}\right)$, the space remains automatically (by contract) let at period $t+1$. Moreover, it also remains let when there is a possible option to leave $\left(t \in S_{i}\right)$ that is not exercised.

(ii) The second issue faced by the landlord is the length of vacancy. Once he has a vacant space in the portfolio it is difficult to rationally infer the length of time for which the space will remain vacant. The length of the vacancy period may be months or even years, and widely varies from one space to another, depending on the state of the submarket, on the location, and on the state and quality of the premises themselves. To model this various possibilities in vacancy length we define the random variable $X$ as the number of periods during which the premises stay vacant. Poisson's law is used to model the vacancy length.

$$
X \sim P(X=k)=\frac{\lambda^{k} e^{-\lambda}}{k !}
$$

Where $k$ is the length of vacancy and $\lambda$ is a positive real number, equal to the expected number of occurrences during the given interval. We illustrate Poisson's law in Figure 1.
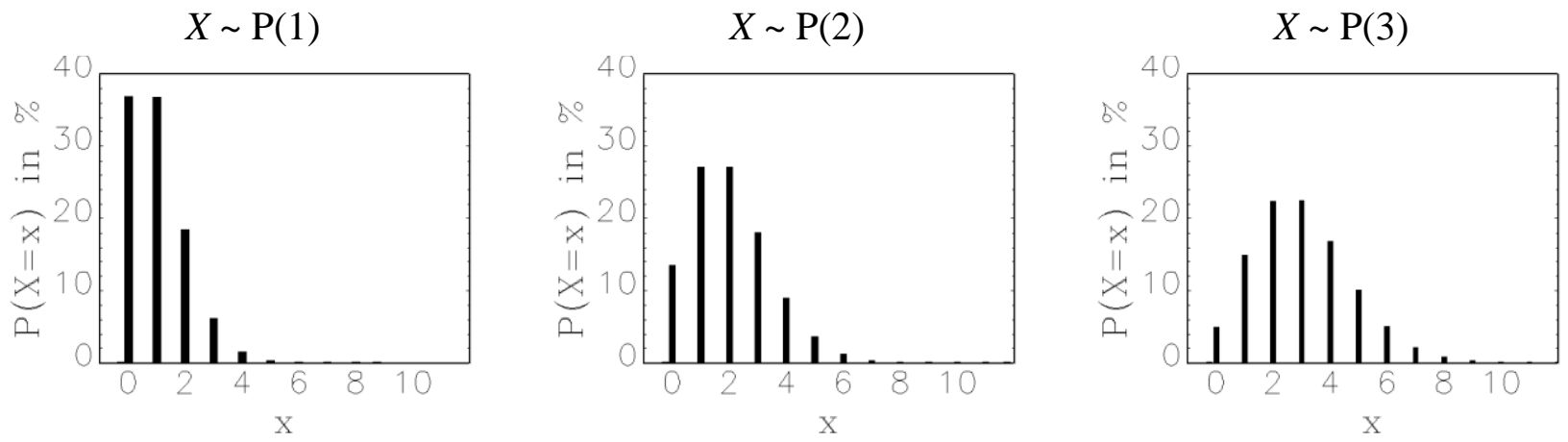

Figure 1. Illustrations of Poisson's law for an average vacancy length of 1,2 and 3 periods

This representation can determine the vacancy length (and its underlying associated probability) independently of the last vacancy period as soon as a known average vacancy length $(\lambda)$ for each submarket is available. This way, the length of vacancy is modeled as a random variable that can take a different value for each simulation, instead of a chance fixed value.

The dynamic between two consecutives periods is summarized in the following transition matrix: 


\begin{tabular}{|c|l|l|}
\multicolumn{1}{|c|}{ Let } & Vacant \\
\hline Let & $\bullet\left\{\begin{array}{l}\text { Break option } \\
\text { Rent }_{t, i} \leq 1+\alpha \\
M R V_{t, i}\end{array}\right.$ & $\bullet\left\{\begin{array}{l}\text { Break option } \\
\text { Rent }_{t, i} \\
M R V_{t, i}\end{array} 1+\alpha\right.$ \\
\hline Vacant & $\bullet$ Let (a tenant was found) & $\bullet$ Vacant \\
\hline
\end{tabular}

\subsection{Cash outflows}

The cash outflows represent the various expenses related to the building arising for the landlord. They are threefold:

- current expenses: linked to regular expenses such as insurance, repairs and maintenance. Let us define $\operatorname{Exp}_{t, i}^{*}$ the expected potential current expenses during the period $t$ for the space $i$ and $v_{t, i}$ the probability of having such expenses. The expected current expenses at period $t$ for the premises $i$ can then be expressed as:

$$
\forall i=1, \ldots, n, \forall t, \operatorname{Exp}_{t, i}=v_{t, i} \times \operatorname{Exp}_{t, i}^{*}
$$

- capital expenses: these are significant expenses related to maintenance or refurbishment which have a direct influence on the value of the asset or its marketability - for instance, roof repairs, ventilation or lift replacement. Let us define $W k_{t, i}$ as the expected potential work (capital expenditure) at period $t$ for the premises $i$ and $\kappa_{t, i}$ as the probability of such work being necessary. These expected capital expenses during period $t$ can be formulated as:

$$
\forall i=1, \ldots, n, \forall t, W k_{t, i}=\kappa_{t, i} \times W k_{t, i}^{*}
$$

- vacancy charges: these correspond to the expenses arising only in case of vacancy, such as land taxes or specific local taxes, heating, cooling, security or marketing expenses (billboard). Let us define $C v_{t, i}^{*}$ as the expected potential vacancy expenses during $t$ for the premises $i$ and $v_{t, i}$ the probability that such expenses will arise. These expected vacancy charges during the period $t$ can be formulated as:

$$
\forall i=1, \ldots, n, \forall t, C v_{t, i}=v_{t, i} \times C v_{t, i}^{*}
$$

\subsection{Free cash flows}

We are now able to determine the free cash flows we will use to compute the present value of the real estate portfolio. These cash flows incorporate simulations of the rents and the behavioral model of the tenant's choice.

The free cash flows generated by the portfolio are principally composed of the cash inflows from rents and tax reduction due to depreciation, the cash outflows associated with expenses, 
and the terminal value, allowing for any capital gains tax. The terminal value, and therefore the incidence of capital gains tax, arises only when the portfolio is sold at the end of the holding period. By assumption and for purposes of simplification, we treat the entire portfolio as being sold at the end of the period under consideration $T$.

The free cash flows of a specific space $i$ at period $t$ from the period $t(t \in[1, T-1])$, where the portfolio is sold at period $T$, are expressed as follow:

$$
\forall i=1, \ldots, n, \forall t=1, \ldots, T-1 \quad F C F_{t, i}=(1-\tau)\left(\operatorname{Rent}_{t, i}-\operatorname{Exp}_{t, i}-W k_{t, i}-C v_{t, i}\right)+\tau D e p_{t, i}
$$

where $\operatorname{Dep}_{t, i}$ is the element of depreciation at time $t$ corresponding to the space $i$ and $\tau$ is the tax rate.

Therefore the free cash flows for period $t=1, \ldots, T-1$, of a portfolio composed of $n$ spaces to let can be evaluated as follow:

$$
\begin{aligned}
& \forall i=1, \ldots, n, \forall t=1, \ldots, T-1 \\
& F C F_{t}=(1-\tau) \sum_{i=1}^{n}\left(\text { Rent }_{t, i}-\operatorname{Exp}_{t, i}-W k_{t, i}-C v_{t, i}\right)+\tau \sum_{i=1}^{n}\left(\operatorname{Dep}_{t, i}\right)
\end{aligned}
$$

The free cash flows at time $T$ at the end of the holding period is equal to:

$$
\begin{aligned}
& \forall i=1, \ldots, n, \\
& F C F_{T}=(1-\tau) \sum_{i=1}^{n}\left(\operatorname{Rent}_{T, i}-\operatorname{Exp}_{T, i}-W k_{T, i}-C v_{T, i}\right)+\tau \sum_{i=1}^{n}\left(\operatorname{Dep}_{T, i}\right)+P_{T}-\tau \times P V
\end{aligned}
$$

where $P_{T}$ is the expected portfolio terminal value at the end of the holding period and PV the capital gain at the end of the investment.

\subsection{Discount Rate Choice}

The choice that has to be made between the cost of equity and the cost of capital in discounting cash flows is an issue in itself, and cannot form part of this paper. As we do not include any debt cash flow in our model, a classical Weighted Average Cost of Capital will be used, and the investor is assumed to be in a situation where this is of relevance. We denote $k$ as the Weighted Average Cost of Capital, used as the discount rate.

\section{Applying a Monte Carlo simulation: simulating prices, market rental values and rents}

To elaborate the model, the terminal value, the MRV and rents (including their indexation) have to be simulated.

\subsection{Terminal value}

Following Baroni, Barthélémy and Mokrane (2007a), our model aims to simulate the price of the portfolio. Indeed, terminal value has a significant impact upon the portfolio valuation, and 
the incorporation of uncertainty in the terminal value is one of the major strengths of the model. We suppose that asset prices are governed by the following geometric Brownian motion.

$$
\frac{d P_{t}}{P_{t}}=\mu_{P} d t+\sigma_{P} d W_{t}^{P}
$$

This equation assumes that commercial real estate returns can be modeled as a simple diffusion process, where parameters $\mu_{P}$ and $\sigma_{P}$ correspond to trend and to volatility. As an example, we present the paths of the price for $P_{0}=0$, and of the histogram of possible prices, with different values of $\mu_{P}$ and $\sigma_{P}$.

As an illustration, Figure 2 uses 5,000 simulated paths to show two different price dynamics with different volatilities, the trend being the same:

- Case 1: $\frac{d P_{t}}{P_{t}}=0.02 d t+0.05 d W_{t}^{P}$

- Case 2: $\frac{d P_{t}}{P_{t}}=0.02 d t+0.10 d W_{t}^{P}$

For each case an estimated density function of the random variable $P_{t}$ is represented for $t=15$ in Figure 3.

Case 1: $\sigma_{P}=0.05$

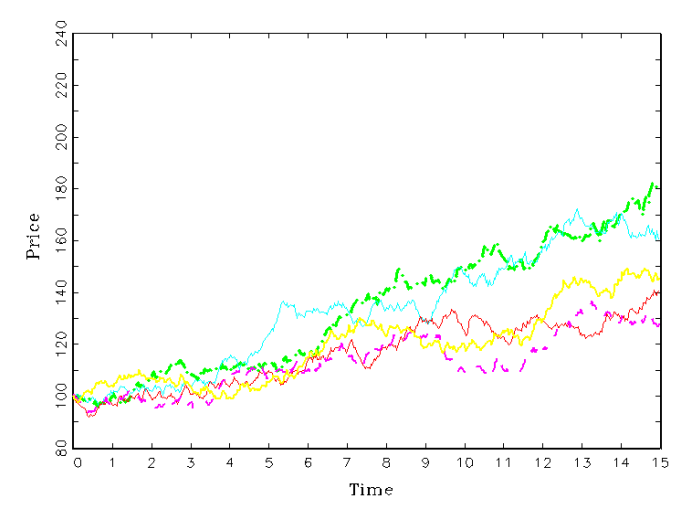

Case 2: $\sigma_{P}=0.10$

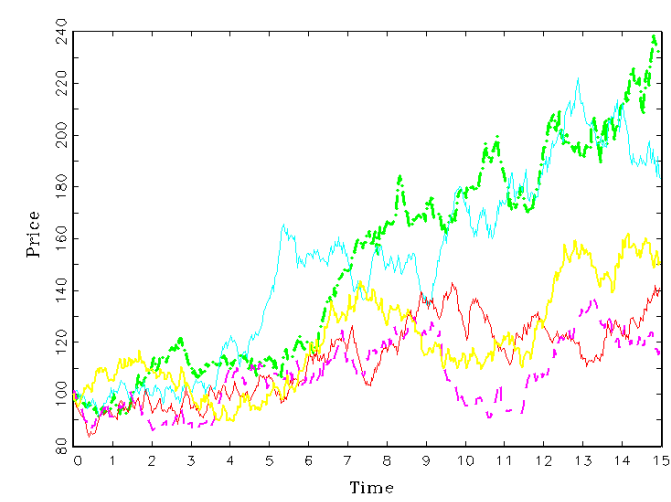

Figure 2. Five simulated price paths

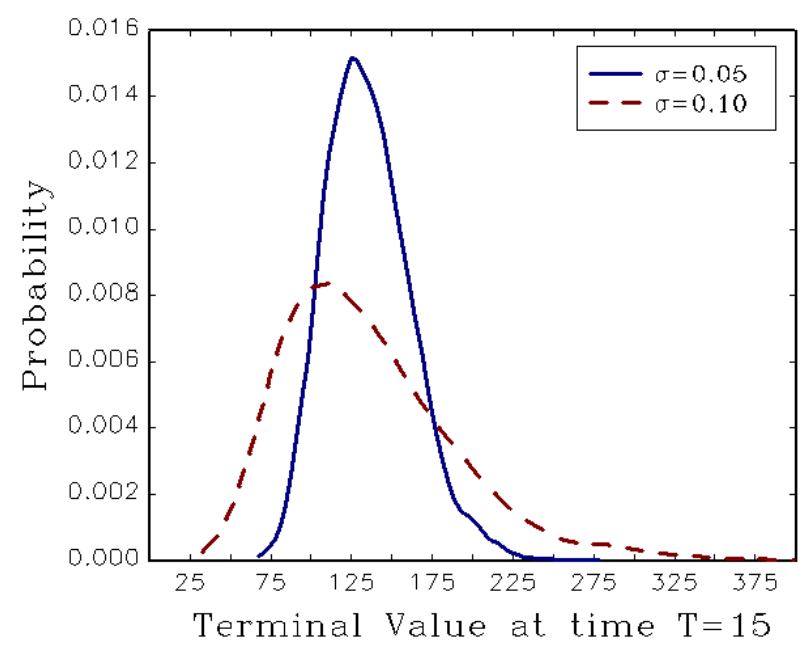

Figure 3. Estimated density function for prices at time $t=15$ 
Each space $i$ that is part of the portfolio generates during period $t$ a rent Rent $t_{t, i}$ (this rent can be equal to 0 ). Each space $i$ also has its own market rental value at time $t$, denoted $M R V_{t, i}^{j}$. This market rental value follows a dynamic based on the index of its specific submarket. Two spaces located in the same submarket will thus have the same market rental value dynamic; however divergences in the values themselves may occur due to differences in size, floor level, or any similar specificity. In brief, we can assume two spaces in the same submarket with different characteristics, following the same dynamics but possibly take different values. We define $I_{t, j}^{M R V^{j}}$ as the index of the market rental value in submarket $j$ during period $t$. We assume in the same way as previously for the price that all the indexes of market rental values are governed by the following geometric Brownian motion:

$$
\forall j=1, \ldots, m, \quad \frac{d I_{t, j}^{M R V^{j}}}{I_{t, j}^{M R V^{j}}}=\mu_{I_{t, j}^{M R V^{j}}} d t+\sigma_{I_{t, j}^{M R V^{j}}} d W_{t}^{I_{t, j}^{M R V^{j}}}
$$

The indexes representing the development of market rental value in all the submarkets are thus defined by their trends and volatilities. Various market rental values can be simulated in order to represent a diversified portfolio invested in different submarkets. To simulate them, the estimation of all the parameters $\mu_{I_{t, j}^{M R V}}$ and $\sigma_{I_{t, j}^{M R V}}$ for all the submarkets $j$ is needed. The market rental value of the space $i$ of the submarket $j$ at time $t$ is therefore given by:

$$
\forall i=1, \ldots, n, \forall j=1, \ldots, m, \forall t, M R V_{t, i}^{j}=f\left(M R V_{t-1, i}^{j}, \Delta I_{t, j}^{M R V_{j}}\right)
$$

The last equation shows the need to start with an initial market rental value $M R V_{0, i}$, $\forall i=1, \ldots, n$, . This is why the initial market rental value has to be estimated.

Furthermore given the dependence - the correlation - between the price of a real estate portfolio and the market rental values that of which this portfolio is composed, it is not possible to simulate the processes independently. It is necessary not only to consider correlations between the indexes of market rental values and price, but also between the market rental values indexes themselves. Consequently the simulation requires an estimation of the correlations between the price and all market rental values indexes, and between the indexes themselves. It is therefore necessary to estimate all the $\rho_{P / I_{t, j}^{M R V}}$ and all the $\rho_{I_{t, j}^{M R V} / I_{t, j}^{M R V}}$ :

$$
\begin{aligned}
& \forall j=1, \ldots, m, \quad \rho_{P / I_{t, j}^{M R V_{j}}}=d W_{t}^{P} d W_{t}^{I_{t, j}^{M R V_{j}}} \\
& \forall j=1, \ldots, m, \quad \forall j^{\prime}=1, \ldots, m, j \neq j^{\prime} \quad \rho_{I_{t, j}^{M R V_{j}} / I_{t, j^{\prime}} M_{j}}=d W_{t}^{I_{t, j}^{M R V_{j}}} d W_{t}^{I_{t, j^{\prime}}^{M R V_{j}}}
\end{aligned}
$$

An illustration is proposed in Appendix 1.

\subsection{Simulation of the rents}

As already detailed in section 2, the lease structure has to be taken into account when simulating the rents. For each lease and at the relevant break dates $\left(t \in S_{i}, \forall i=1, \ldots, n\right.$, ), the 
market rental value of each space is compared to the current rent, and the model decides if the option to leave has to be exercised or not.

For illustrative purposes, we present in Figure 4 all the possible cases that may occur for a classical French commercial lease in the specific case where the vacancy length is fixed for one year. This traditional French lease takes the form of a nine year contract with two break options: to leave the premises before the end of the contract at the end of years 3 and 6 . Let us consider periodical indexation set to $2.5 \%$. The market rental value is fixed as 100 during the course of the lease. The lease begins at the first period $t=1$. Four cases may occur in Figure 4:

(a) The space remains let during the course of the lease and no break options are exercised;

(b) The first break option (end of period 3) is exercised. After one year of vacancy, a new tenant enters the premises and stays until the end of the new lease;

(c) The second break option (end of $6^{\text {th }}$ period) is exercised. A new tenant enters the space after one year of vacancy;

(d) The first break option is exercised by each current tenant each time it this option arises. Therefore the landlord faces two years of vacancy during the $4^{\text {th }}$ and the $8^{\text {th }}$ period.

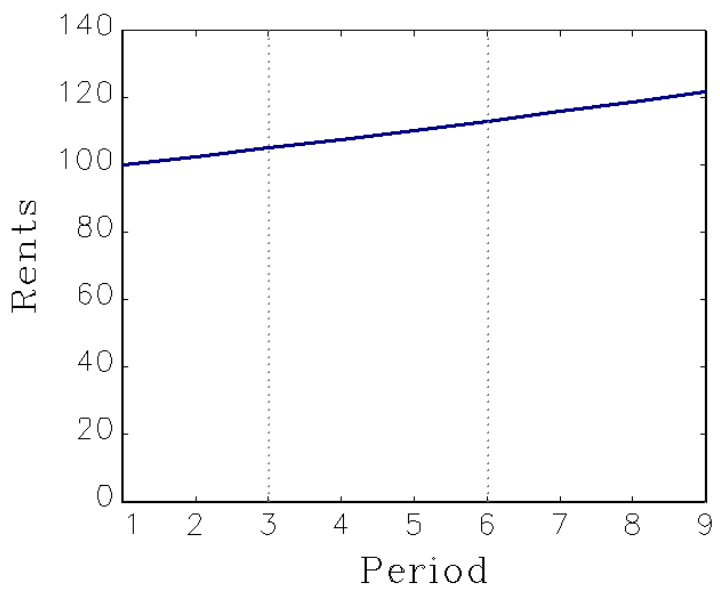

(a)

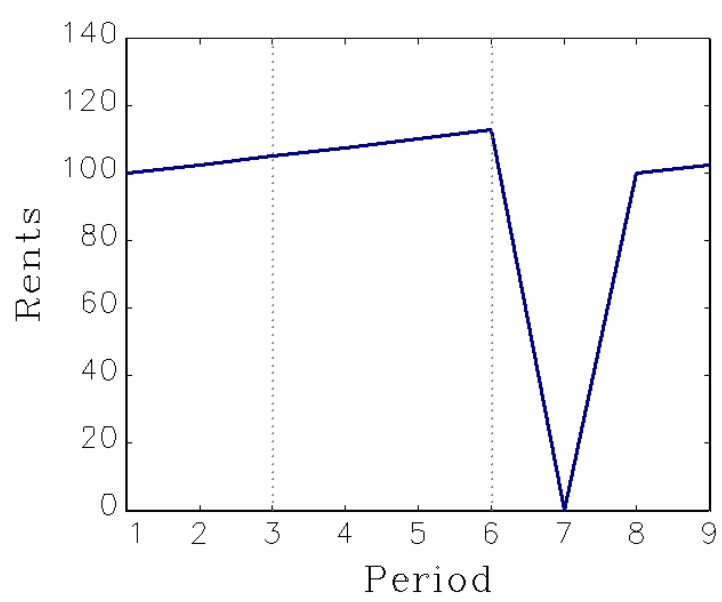

(c)

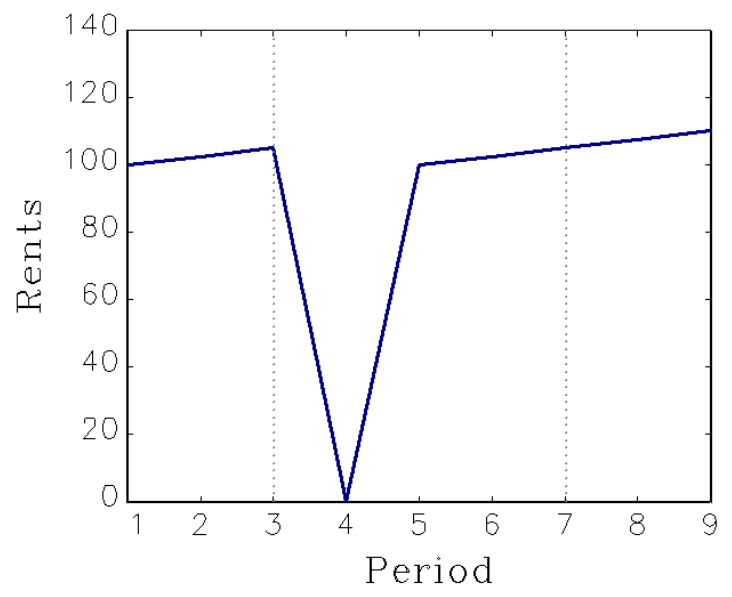

(b)

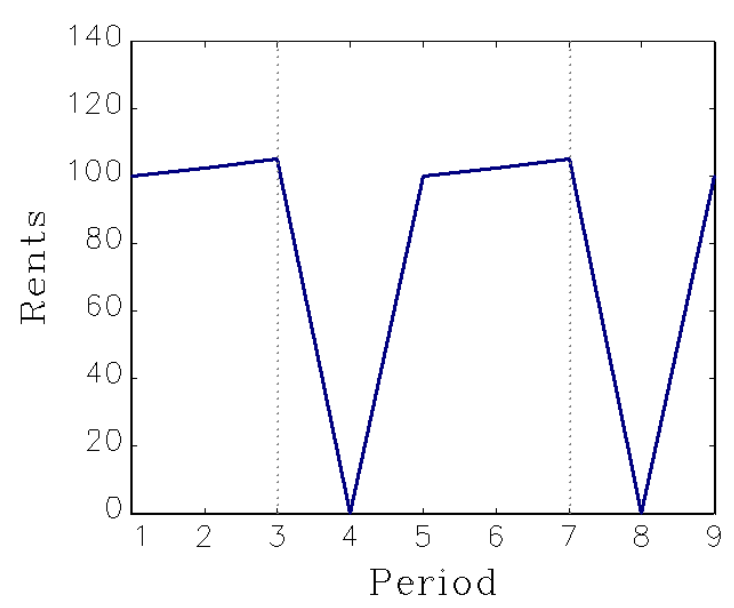

(d)

Figure 4. The four possible cases of a French lease contract 
In all the cases shown above, the rent returns to the market rental value after each break option is exercised. As such, the break option is an opportunity for the tenant, or a risk for the landlord.

\subsection{Simulation of the rents and of the market rental value}

We now introduce the market rental value and the rent received, taking into account the dynamics represented by vacancy length. Figure 5 present the rents resulting in six simulated cases for a French lease contract ( 9 year lease with break options at year 3 and 6) over 15 years using our model. The bold line represents the rents paid and the lighter line represents the market rental value. In these graphs the rent is indexed annually at a rate of $2.5 \%$, the average vacancy length equals 2 years $(\lambda=2)$; and we have assumed that the tenant decides to move as soon as his rent is higher than the market rental value at the date of a break option ( $\alpha=0)$. The market rental value index follows a dynamic given by $N(0.02 ; 0.1)$. Figure $5(\mathrm{f})$ is a case where no rent is paid during the initial periods.

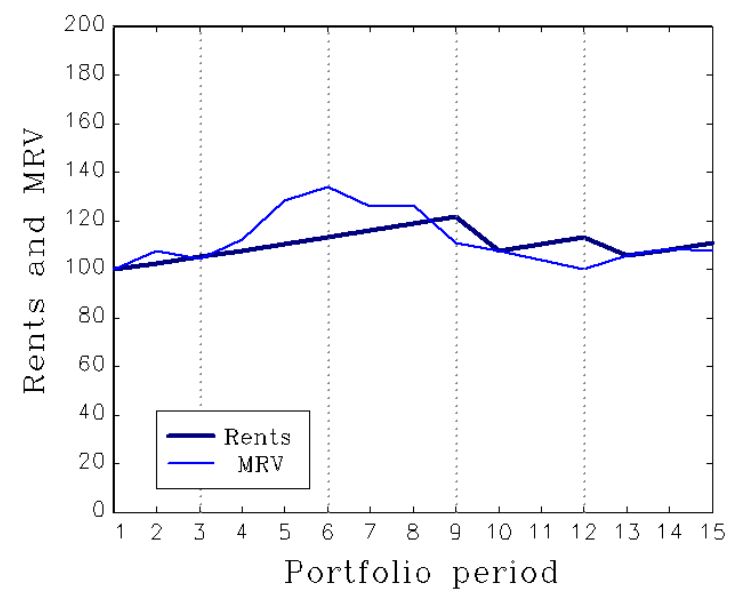

(a)

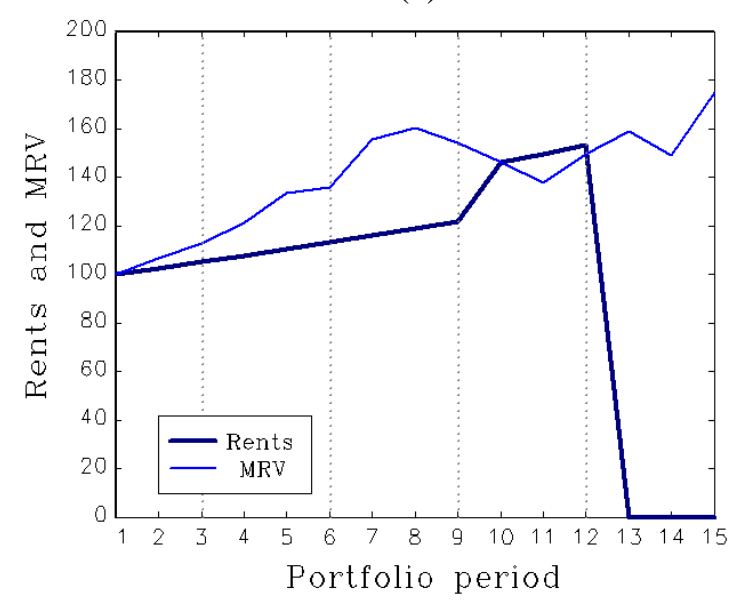

(c)

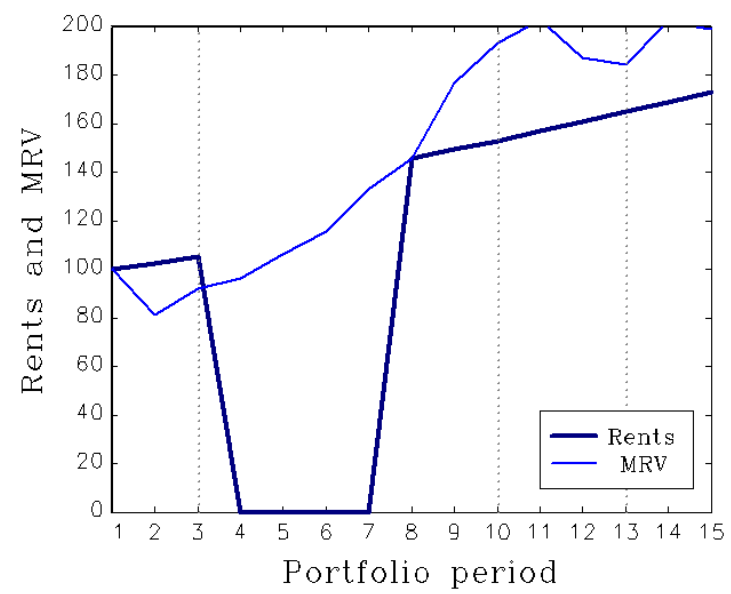

(b

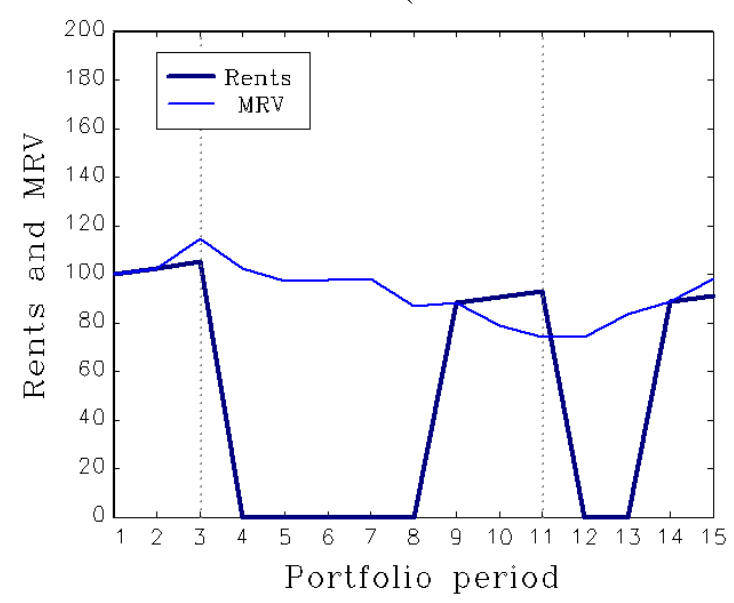

(d) 


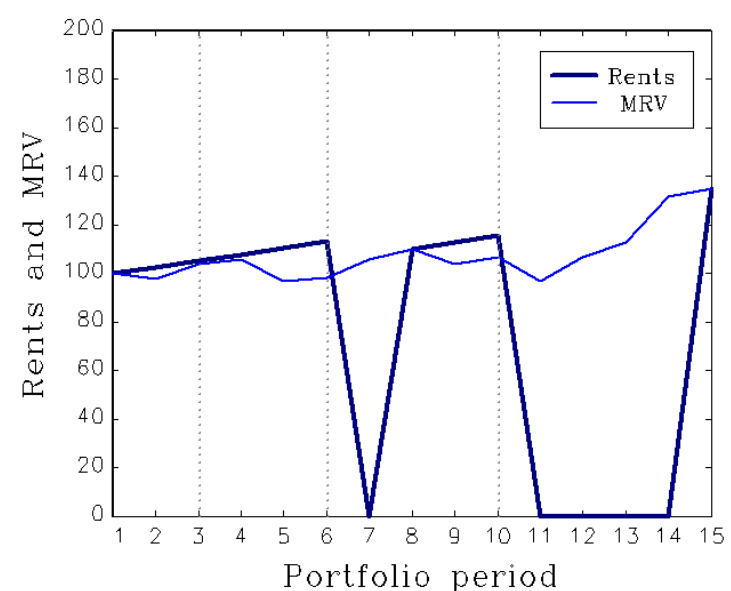

(e)

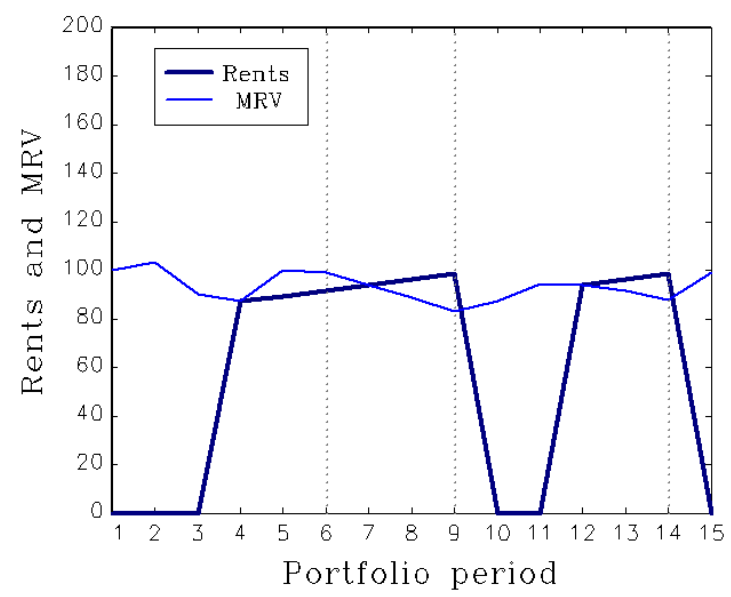

(f)

Figure $5^{i i i}$. Six illustrations of our methodology used in the case of a French lease contract

The Monte Carlo method creates a large number of scenarios. Each simulated scenario presents the rents paid by one space during the simulation. By repeating this hundreds of times we calculate the average of all the simulations and obtain the rents expected during the period. Figure 6 represents three paths for the rents, the market rental value and of their combination in the case of a French lease contract. Then in Figure 7 we represent the average of the rents and of the market rental values for this lease (3/6/9). As before, the market rental values are driven by $N(0.02 ; 0.10)$ and the rent is indexed at $2.5 \%$ per year. The average vacancy length equals 2 years $(\lambda=2)$ and we assume $\alpha=0$.
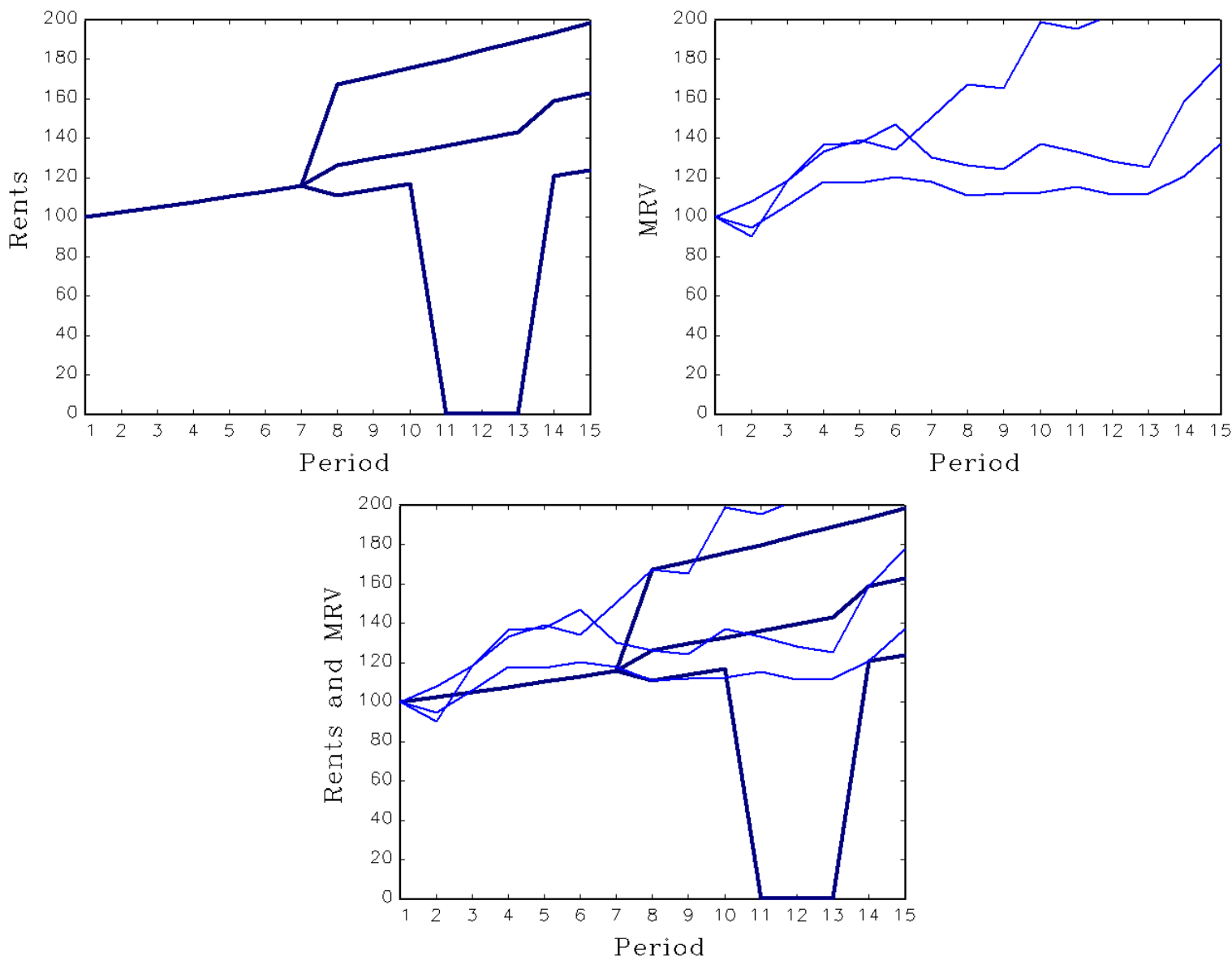

Figure 6. Three paths for the market rental value and for rents in the case of a French lease contract. 


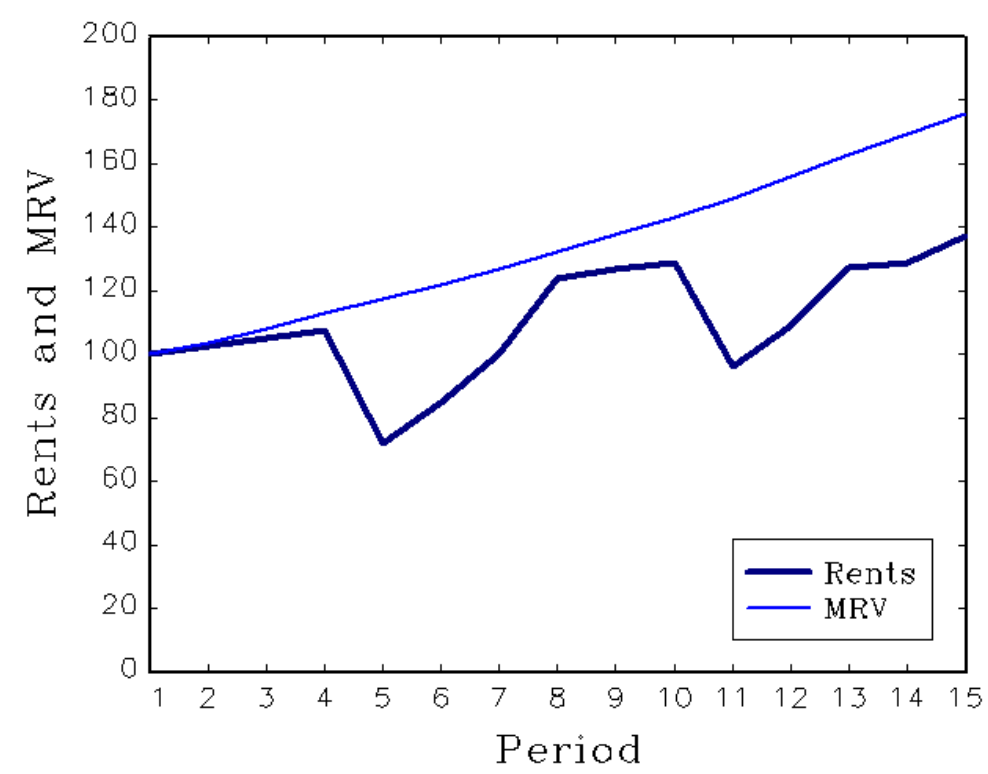

Figure 7. Average of 10,000 scenarios for rents and market rental values in a French lease contract

\subsection{Distribution of rents}

To illustrate the relevance of the model we present the histogram of the rents paid on a French lease contract for each period. The lease under consideration is assumed to have been signed initially for 9 years with 2 break options at years 3 and 6 . When broken, and after the vacancy period, the new lease is contracted under the same terms (3/6/9). Figure A.2 in Appendix 2 shows the change owing to the lease structure, and highlights the importance of taking the options offered to the tenant in the lease contract into account.

\subsection{Simulation of the free cash flows}

In this section the simulations both of rents and of the terminal value of the portfolio are now combined. The classical discounted cash flow model is used to price the net present value of the real estate portfolio. All future free cash flows are discounted at the discount rate $k$. This enables us to confer a value on the portfolio.

$$
P_{0}=\sum_{\theta=1}^{T-1} \frac{F C F_{t}}{(1+k)^{\theta}}+\frac{F C F_{T}}{(1+k)^{T}}
$$

Or more precisely:

$$
P_{0}=\sum_{\theta=1}^{T} \frac{(1-\tau) \sum_{i=1}^{n}\left(\text { Rent }_{t, i}-\operatorname{Exp}_{t, i}-W k_{t, i}-C v_{t, i}\right)+\tau \sum_{i=1}^{n}\left(\text { Dep }_{t, i}\right)}{(1+k)^{\theta}}+\frac{P_{T}-\tau \times P V}{(1+k)^{T}}
$$

Applying Monte Carlo methodology, the process is repeated hundreds times and we obtain a large number of prices for the portfolio. The average of all these values can be used as an estimate of the value of the portfolio.

The parameters that have to be known or estimated to implement the model are the following:

- The trend and volatility of the price: $\mu_{P}$ and $\sigma_{P}$ 
- The trends and volatilities of all the market rental value indexes $\mu_{I_{t, j}^{M R V}}$ and $\sigma_{I_{t, j}^{M R V}}, \forall j=1, \ldots, m$

- The correlations between all the simulated processes.

The lease structures of each space, the initial rents and the indexations for each lease are known by contract. The initial market rental values, the initial price and the tax rate are observable. The discount rate $k$ corresponds to the Weighted Average Cost of Capital. The depreciation rate and its impact on the cash flows are country specific and also observable. For the purposes of simplification expenditure growth is supposed to be constant, but if necessary (and if enough information is available) it could be also simulated.

The next section deals with the valuation of a portfolio, and will provide more detail on the free cash flow simulations.

\section{Application of the model}

\subsection{Valuation of a portfolio}

In this section, and using the previous framework, we simulate both the cash flows generated by the leases and the terminal value of a commercial real estate portfolio. The methodology is based on the modeling of rents, expenditures, and price dynamics. We provide a model that can be used by investors to analyze portfolio risk associated with the lease structure. We also test the robustness of the model by using a sample.

The model preserves a significant degree of freedom for all the considered variables and their possible relationships/correlations. The modeling allows for the incorporation of experiences from real estate portfolio managers or local agencies. An asset manager might for example have empirical knowledge of a portfolio's ability to maintain tenants, or may be an especially skilled negotiator, and may then use these in the simulation. The greater the experience, the better the model should be for use in simulations, in the sense that the dynamics represented in the model should be closer to reality.

We take one example to compute the value of and the annual inflows from a given portfolio on a 15-year period. We show in Figure 8 the histogram of the possible rents produced by the portfolio for each year. In the following we focus particularly on the parameters that have the greatest impact upon the tenant's behavior and the valuation of the portfolio: vacancy length $(\lambda)$, and the difference between the market rental value and rents whose level prompt the tenant to move $(\alpha)$.

The commercial real estate portfolio we consider is a real portfolio composed of 16 lettable spaces. The portfolio comprises 6 properties. The properties were acquired during their construction between the years 2005 and 2009 (the last completion of a building). The complete portfolio was sold in 2010 for $100 \mathrm{M} €$. All the spaces are located in the suburbs of Paris, France; They all are considered to be driven by the same submarket index, therefore $j=$ 1 ( $j$ is the number of submarkets for the market rental value index $I_{t, j}^{M R V^{j}}$ ). The submarket 
index is supposed to follow a normal law $N(0.04 ; 0.08)$ and therefore the market rental values of the spaces follow this law $N(0.04 ; 0.08)$.

$\forall t, I_{t, 1}^{M R V^{1}} \sim N(0.04 ; 0.08), j$ being unique in our case (same submarket);

Regarding the annual review of the rent, we consider for purposes of simplification a fixed increase of $2.5 \%$ per year (in practice, differences often occur with maximum indexation: a cap, fixed indexation, or sometimes upward revision only):

$\forall t, \forall i, I_{t, 1}^{\text {Rent } t, i}=2.5 \%$

The passing rents and rental values of all the premises at the time of acquisition are displayed in Table 1. One space identified with lease 14 is initially vacant, some are under-let - the initial rent is priced below the market price - as is the case of the leases $8,9,10,11$; some are over-let - the initial rent is priced above the market price - it is the case of the leases 1, 2, 4, $5,13,16$. The remaining part of the portfolio is let at the market price: leases $3,6,7,12,15$. Very simply and without any simulation we can predict which tenant may be more difficult to maintain in the asset. Holders of over-let leases will be more tempted to move to cheaper places.

Table 1. Passing rents produced and rental values of the 16 premises

\begin{tabular}{ccc}
\hline (in $€$ ) & $\begin{array}{c}\text { Market rental values of the } \\
\text { spaces at acquisition }\end{array}$ & Passing rents at acquisition \\
\hline Lease 1 & $1,000,000$ & $1,100,000$ \\
Lease 2 & 500,000 & 550,000 \\
Lease 3 & 300,000 & 300,000 \\
Lease 4 & 500,000 & 550,000 \\
Lease 5 & 600,000 & 620,000 \\
Lease 6 & 150,000 & 150,000 \\
Lease 7 & 600,000 & 600,000 \\
Lease 8 & 700,000 & 650,000 \\
Lease 9 & 600,000 & 550,000 \\
Lease 10 & 500,000 & 450,000 \\
Lease 11 & 600,000 & 550,000 \\
Lease 12 & 300,000 & 300,000 \\
Lease 13 & 300,000 & 330,000 \\
Lease 14 & 150,000 & 0 \\
Lease 15 & 500,000 & 500,000 \\
Lease 16 & 200,000 & 220,000 \\
\hline TOTAL & $\mathbf{7 , 5 0 0 , 0 0 0}$ & $\mathbf{7 , 4 2 0 , 0 0 0}$ \\
\hline
\end{tabular}

The portfolio is bought whole in one period. Therefore the buyer acquires a portfolio which is already constituted and under management. The properties have been marketed and have been let for different periods, and the leases are running with various maturity dates and various lease structure type. The current lease structure of the premises is displayed in Table 2.

Table 2. Current lease structure of the portfolio 


\begin{tabular}{|c|c|c|c|c|}
\hline $\begin{array}{l}\text { period of } \\
\text { acquisition }\end{array}$ & $\begin{array}{c}\text { First period of } \\
\text { break option }\end{array}$ & $\begin{array}{c}\text { Second period of } \\
\text { break option }\end{array}$ & $\begin{array}{c}\text { Third period of } \\
\text { break option }\end{array}$ & End of lease \\
\hline Lease 1 & 6 & & & 9 \\
\hline Lease 2 & 3 & & & 6 \\
\hline Lease 3 & 4 & & & 7 \\
\hline Lease 4 & & & & 3 \\
\hline Lease 5 & 1 & & & 4 \\
\hline Lease 6 & 2 & 5 & 8 & 11 \\
\hline Lease 7 & 6 & & & \\
\hline Lease 8 & 1 & & & 7 \\
\hline Lease 9 & & & & 2 \\
\hline Lease 10 & & & & 8 \\
\hline Lease 11 & 1 & & & 4 \\
\hline Lease 12 & & & & 5 \\
\hline Lease 13 & 6 & & & 9 \\
\hline \multicolumn{5}{|l|}{ Lease 14} \\
\hline Lease 15 & 5 & & & 8 \\
\hline Lease 16 & 2 & 5 & 8 & 11 \\
\hline
\end{tabular}

Among the leases in the portfolio some of them have just been contracted, some terminate within a short period of time, and some are longer term and face numerous break options. The leases share in common the fact that they almost all started before the purchase date of the portfolio. Period 1 corresponds to the period between date $0(t=0)$ and date $1(t=1)$. Therefore, a tenant that faces a break option in year 1 will pay his rent once and can then break the lease at the end of the first year. This is illustrated in the Figure A.3 in Appendix 3.

If a space becomes vacant a new lease has to be drawn up. This can be done under a predefined lease structure after a period of vacancy, or immediately after the lease terminates. The lease structures are mainly dependent on the size and configuration of the premises to let and on the targeted potential tenants. The lease structures applicable to the successor tenant are displayed in Table 3. For example, if lease 10 is broken, the subsequent tenant enters the property under a traditional French leasing contract (3/6/9).

Table 3. Lease structure of all the premises of the portfolio in case of re-letting

\begin{tabular}{|c|c|c|c|c|}
\hline $\begin{array}{l}\text { In case of a } \\
\text { new contract }\end{array}$ & $\begin{array}{c}\text { First period of } \\
\text { break option }\end{array}$ & $\begin{array}{c}\text { Second period of } \\
\text { break option }\end{array}$ & $\begin{array}{c}\text { Third period of } \\
\text { break option }\end{array}$ & End of lease \\
\hline Lease 1 & 6 & & & 9 \\
\hline Lease 2 & 6 & & & 9 \\
\hline Lease 3 & 3 & 6 & & 9 \\
\hline Lease 4 & 6 & & & 9 \\
\hline Lease 5 & & & & 9 \\
\hline Lease 6 & 3 & 6 & 9 & 12 \\
\hline Lease 7 & 6 & & & 9 \\
\hline Lease 8 & 6 & & & 9 \\
\hline Lease 9 & 6 & & & 9 \\
\hline Lease 10 & 3 & 6 & & 9 \\
\hline Lease 11 & 6 & & & 9 \\
\hline Lease 12 & & & & 9 \\
\hline Lease 13 & 6 & & & 9 \\
\hline Lease 14 & 3 & 6 & & 9 \\
\hline Lease 15 & 6 & & & 9 \\
\hline Lease 16 & 3 & 6 & 9 & 12 \\
\hline
\end{tabular}


The initial price of the portfolio is supposed to amount to $100 \mathrm{M} €$ and the price to follow a geometric Brownian motion driven by a Normal law $N(0.02 ; 0.1)$. The correlation between the price and the rental submarket index equals $60 \%$. The entire portfolio is invested in the same submarket (a district in Paris). The void length follows a Poisson's law of parameters 0.5 (average vacancy length is 2 years). The discount rate $k$ is constant during the simulation and fixed at $6.5 \%$. We assume that no arbitrage is possible during the holding period. Furthermore, as stated above, all the cash flows are annual and occur at the same date. The investor is assumed to be a transparent fund not subject to taxes $(\tau=0)$ (see Baroni et al., 2001; Hoesli et al., 2006). For simplification purposes, and to clarify the results, we do not take account of any expenses (current expenditure, capital expenditure or vacancy charges). We show in Figure A.4 in Appendix 4 the distribution of the rents during the 15 years of the simulation.

In Figure 8, we show the average rents and market rental values produced by the portfolio through the simulations.

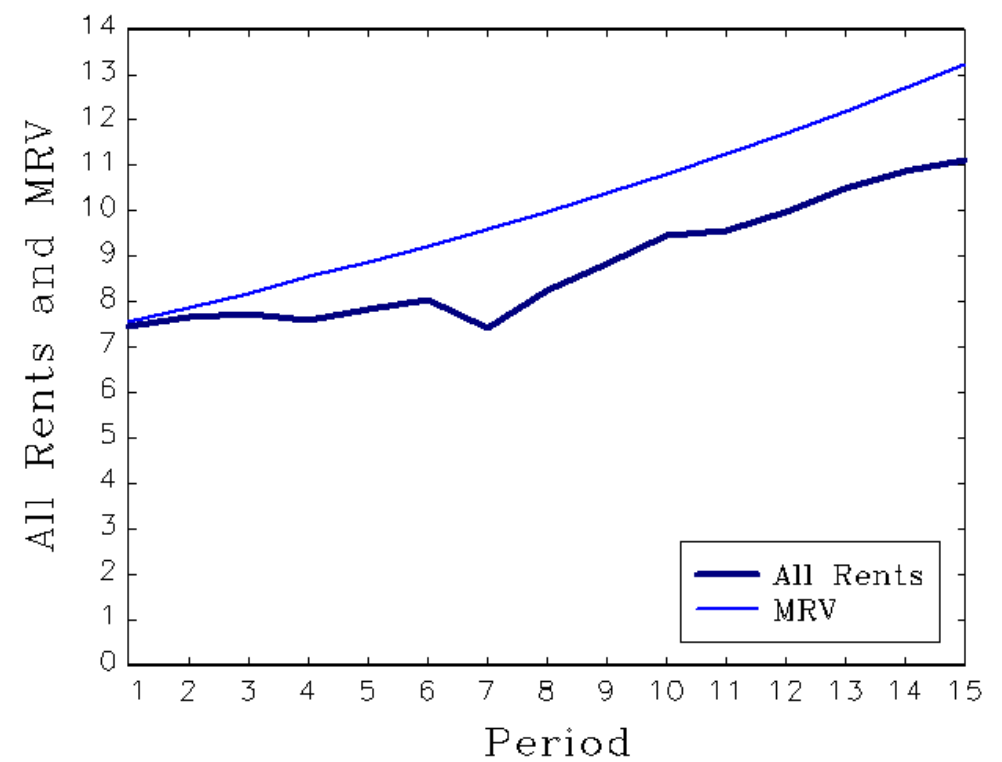

Figure 8. Average rents and market rental value produced by the portfolio

The model can also display the average rents paid for each lease. Risky leases can therefore be forecast and analyzed, which can be assist any decision.

\subsection{Sensitivity analysis and the model's limitations}

In this section we analyze the sensitivities of the model to the length of vacancy $(\lambda)$ and to the criteria for the decision to move $(\alpha)$. We highlight the robustness of the model, but also note some of its limitations. The sensitivity analysis is carried out using the previous portfolio under the same initial conditions. The only changes are $\lambda$ and $\alpha$.

Both these parameters have an impact on the vacancies. The criterion for the decision to move is likely to increase or decrease the number of break options exercised and therefore must have a very large impact on the level of vacancies in the portfolio. On the other hand, the average length of vacancy determines how long a space remains vacant, and therefore how 
long it may generate costs instead of revenues. The graphs represent the sum of expected rents (Figure 9, 10 and 11), the portfolio value (Figure 12) and their associated standard error.

As predicted, the level of expected rents decreases when the length of vacancy increases. At the same time the level of rents decreases when the moving criteria decision is more strictly applied ( $\alpha=0$ for instance). It is interesting to note that the level of rents produced by the portfolio is more strongly affected by the length of vacancy over time than by the moving criteria. This is due to the lease structure. Once a tenant is signed up with a new lease contract at a rent close to the market rental value a predictable income is usually secured for some years, and so the impact on cash flow is far less. The level of risk associated with these two parameters is represented by the standard errors. The graph demonstrates that these two parameters have a very large influence on the risk of the portfolio value, and also on the risk associated with the resulting cash flows. This result is consistent with the usual fear on the part of investors concerning the risk of vacancy in their buildings. Usually they understand this possible vacancy to consist in the costs that it generates and the time it takes to re-let. The results strengthen the evidence that vacancy is the most important factor affecting the value of a classical asset (for high-yielding assets, vacancy has a higher impact in respect of cash flow volatility than low-yielding assets). At the same time, the volatility of the cash flows is barely affected by the length of vacancy when the costs of moving are high. This highlight the interest investors as a whole may have in making specific enhancement chargeable to the tenants so that improved future cash flows might be secured. According to this framework, landlords should only accept paying for maintenance or refurbishment in exchange for the surrender of break options.
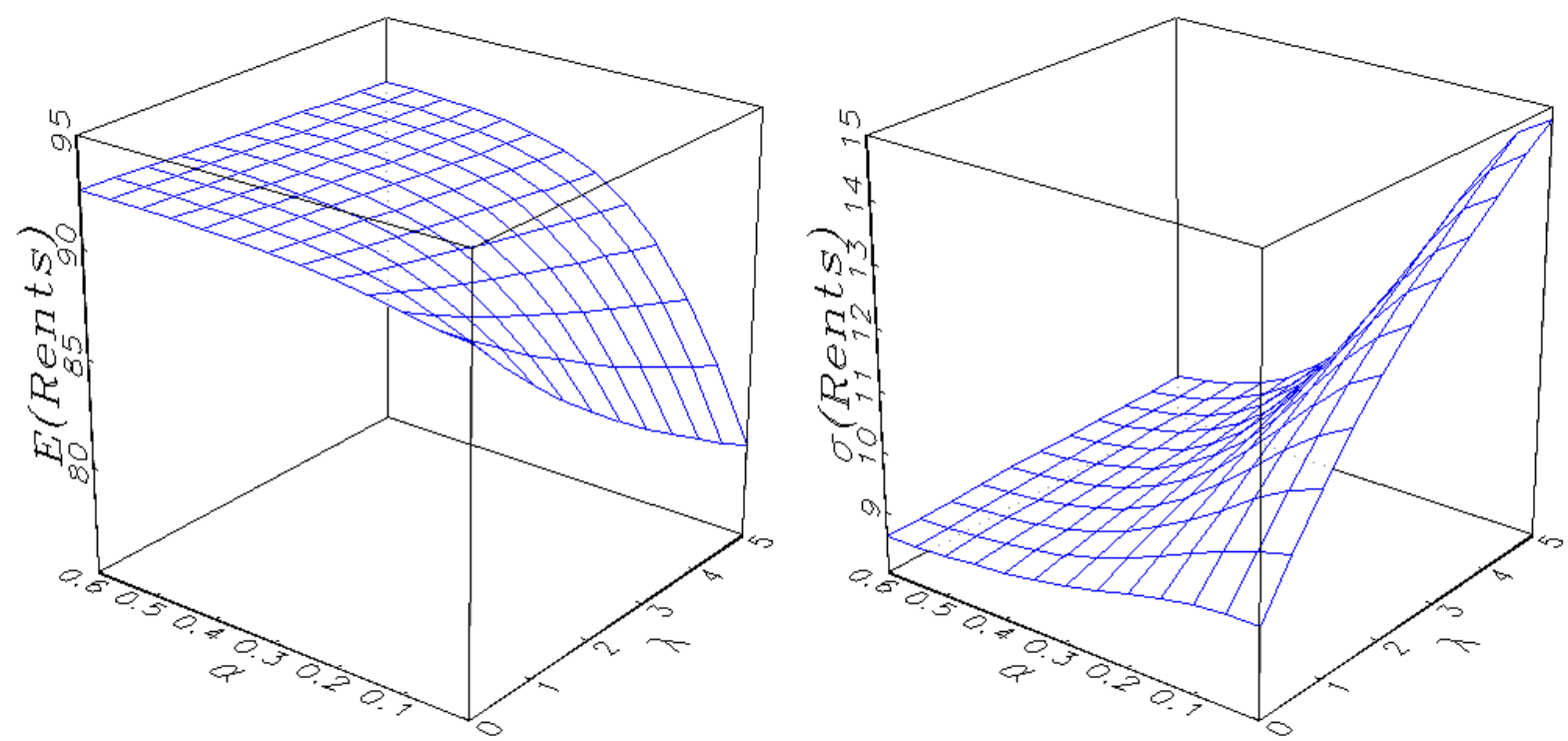

Figure 9. Expectation and standard error of the rents of the portfolio as a function of the moving criteria decision $(\alpha)$ and the expected length of vacancy $(\lambda)$. 

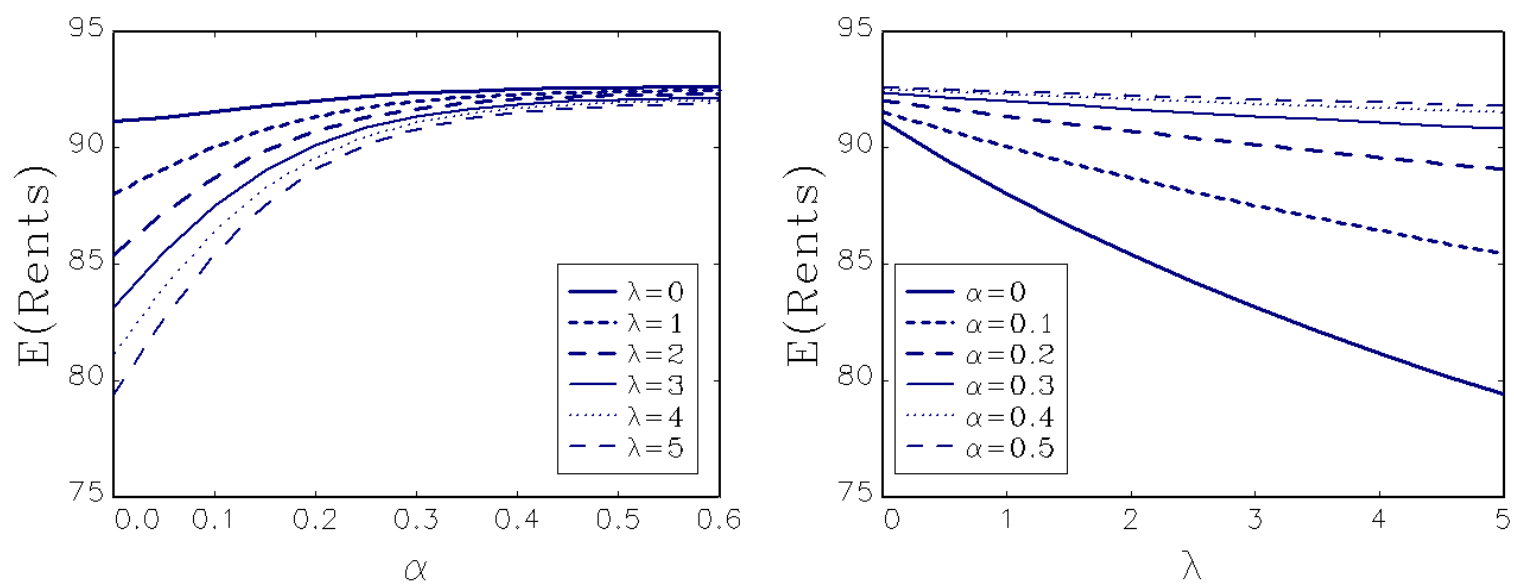

Figure 10. Expectation of the rents of the portfolio as a function either of the moving criteria decision $(\alpha)$ or the expected length of vacancy $(\lambda)$.
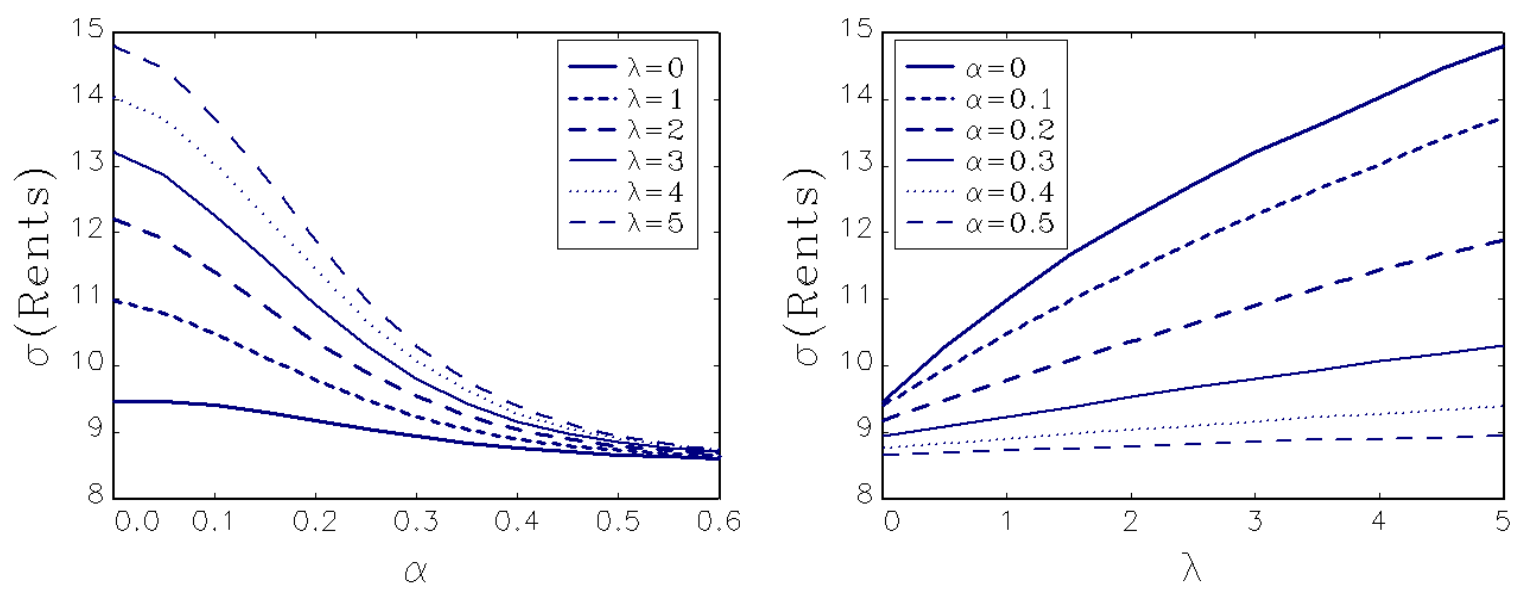

Figure 11. Standard error of the rents of the portfolio as a function either of the moving criteria decision $(\alpha)$ or the expected length of vacancy $(\lambda)$.
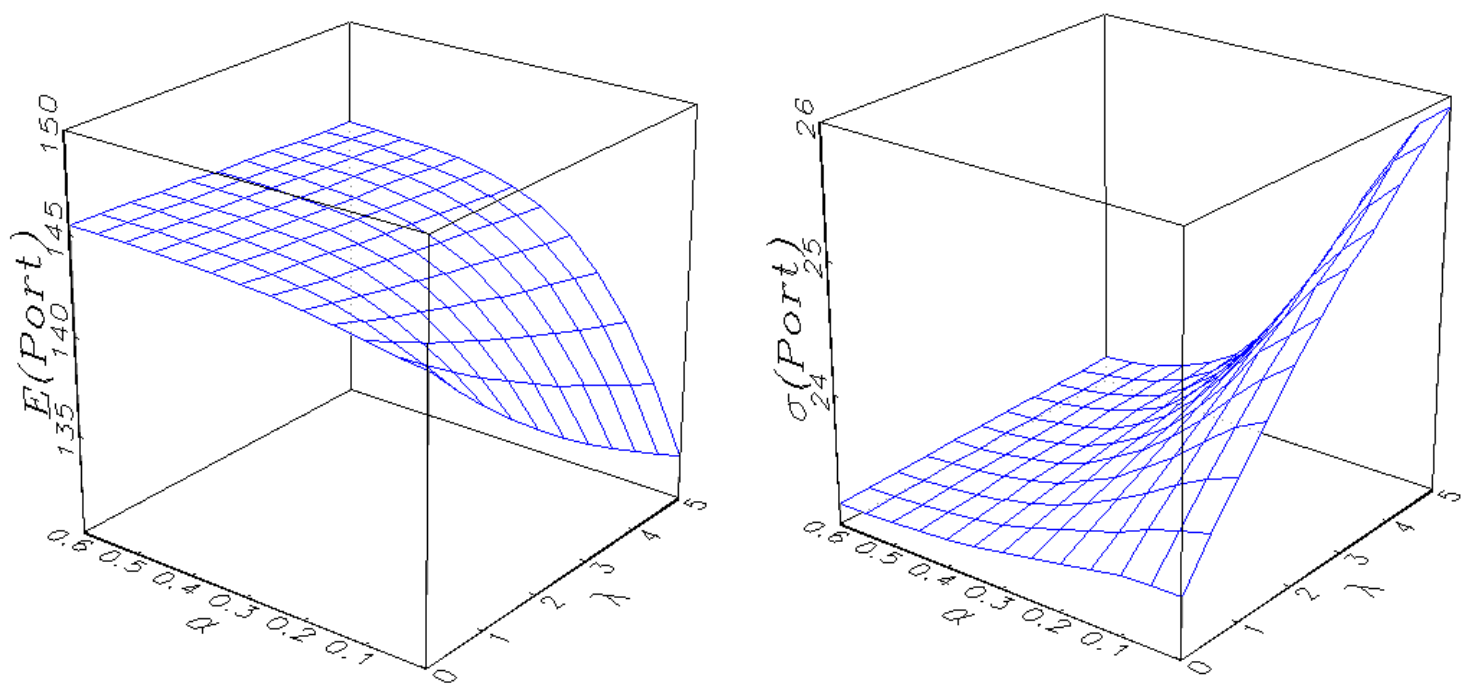

Figure 12. Expectation and standard error of the price of the portfolio as a function of the moving criteria decision $(\alpha)$ and the expected length of vacancy $(\lambda)$. 
We have now presented and tested our model and its relevance. However, this model suffers from some limitations.

One of the first and most obvious limitations lies in the assumption of rational behavior on the part of a tenant. Although this assumption is classical, it is not always verified. Tenants do not always behave rationally in the sense of only being driven by financial considerations; although commercial real estate is primarily seen as a factor of production. Many other factors affect their decision to move: the availability of space, social impact, the routine, communications, possible mergers or acquisitions.

However, even if this assumption is questionable, we do not believe it represents a major issue. Indeed, and particularly in continental Europe, rents are usually in line with the market rental values available for similar premises; and this is precisely because of the prospects of a break option being open to tenants. Negotiations over rents are common when break options are approaching. In these cases the landlord is likely to concede financial incentives (free rent or improvements) or even a rent reduction so that vacancy or a movement to a new longer lease contract might be avoided. Further research including utility functions could help deal with this limitation.

Another limitation in our model is inherent to real estate as an asset class. This is mostly to do with the lack of data. We implicitly supposed that the market rental values and the terminal value of the portfolio are both driven by a normal law, in the absence of data that could define a more specific law. This assumption is weak but common. It does not affect the relevance of the model. Indeed, the model can be adapted by using another law or other simulating methodologies (bootstrapping, neuronal methods, introducing extreme values etc.). The major difficulty lies in the lack of data on all periods. In continental Europe indexes are generally annual (sometimes biannual) and do not really cover all the submarkets in which the various portfolios are invested. Thus it is difficult to calibrate a model with such scanty data. The UK is an exception in having monthly indexes; but unfortunately UK leases have hitherto been characterized by their length and lack of break options (generally only an upward only rent review every five years), and therefore our model is probably less applicable to this country.

\section{Conclusion}

In this paper we have proposed a new methodology for the valuation of a real estate portfolio using Monte Carlo simulations and options to compute its price. In doing so we have suggested a way of incorporating lease structure risk into the valuation process. The principal improvement of our proposal is the possibility of taking account of the break options given to tenants in different lease structures. The proposed model is able to consider tenant behavior with regard to cash flows and therefore show its impact on the portfolio value by combining Monte Carlo methods for the price of the portfolio with the various market rental values. For each simulated scenario, and for each lease at the time of a break option, we compare the current rent with the market rental value available for similar space, and use an assumption of financial rationality to decide whether the tenant moves away or not. The length of vacancy is determined by Poisson's law. From the viewpoint of a practitioner. the model can be used to compute more robust valuations of a real estate portfolio. Practitioners should also find 
interesting the possibility that the model confers of displaying a histogram or a distribution function instead of a fixed value. The main problem in application would be to find all the inputs the model requires, such as the trends and volatilities of each submarket. At the same time our approach is very flexible; many parameters can be introduced and applied in order to suit the specific assumptions and needs of each investor.

Furthermore, this research opens the way to many other fields of real estate finance, such as risk management. We have demonstrated, using sensitivity analysis, the extent to which knowledge of cash-flows may be of valuable assistance in risk measurement, and in developing negotiations between landlord and tenant. By using Monte Carlo methods we obtain a range of possible outcomes instead of a fixed result. The risk associated with a portfolio or a specific asset is thereby better estimated. In particular, the model, along with the distribution of its results, allows us to compute the Value-at-Risk of a portfolio. Such risk measurements are increasingly required by both regulators and investors. Developing our approach in this direction, to provide more robust tools for the management or assessment of risks, could be the objective of future research.

\section{Acknowledgement:}

This research was supported by Fondation Palladio, a French foundation which supports real estate research and education under the aegis of Fondation de France. The views expressed herein are those of the authors and are not necessarily those of Fondation Palladio. 


\section{References:}

Achour-Fischer, D. (1999). "Is there a Myers way to value income flows?," Working Paper, Curtin Business Scholl, Perth.

Baroni, M., Barthélémy, F. and Mokrane, M. (2005). "Physical real estate: a Paris repeat sales residential index," Journal of Real Estate Literature, vol. 13, pp. 303-24.

Baroni, M., Barthélémy, F. and Mokrane, M. (2007a). "Using rents and price dynamics in real estate portfolio valuation," Property Management, vol 25(5), pp. 462-86.

Baroni, M., Barthélémy, F. and Mokrane, M. (2007b). "Optimal holding period for a real estate portfolio," Journal of Property Investment and Finance, vol 25(6), pp. 603-25.

Barthélémy, F. and Prigent, J-L. (2009). "Optimal Time to Sell in Real Estate Portfolio Management," The Journal of Real Estate Finance and Economics, vol. 38(1), pages 59-87.

Cox, C.J., Ingersoll, J.E. and Ross, S.A. (1985). "A theory of the term structure of interest rates," Econometrica, vol. 7, pp. 94-111.

Dupuy, E. (2003). "Real Estate options Risks Analysis of cash Flows: taking real estate risk analysis forward," mimeo, ERES 2003 Conference.

Fama, E. and French, K. (1989). "Business conditions and expected returns on stocks and bonds," Journal of Financial Economics, vol. 15, pp. 305-30.

Ferson, W.E and Campbell, H.R. (1991). "The Variation of Economic Risk Premiums," Journal of Political Economy, vol. 99(2), pp. 385-415.

French, N. and Gabrielli, L. (2004). "The uncertainty of valuation," Journal of Property Investment and Finance, vol. 23(6), pp. 485-500.

French, N. and Gabrielli, L. (2005). "Discounted cash flow: accounting for uncertainty," Journal of Property Investment and Finance, vol. 23(1), pp. 75-89.

Geman, H. (2005). "Commodities and Commodity Derivatives: Pricing and Modelling Agricultural, Metals and Energy." Wiley Finance.

Hoesli, M., Jani, E. and Bender, A. (2006). "Monte Carlo simulations for real estate valuation," Journal of Property Investment and Finance, vol. 24(2), pp. 102-22.

Kelliher, C.F. and Mahoney, L.S. (2000). "Using Monte Carlo simulation to improve long-term investment decisions," The Appraisal Journal, vol. 68, pp. 44-56.

Li, H.L. (2000). "Simple computer applications improve the versatility of discounted cash flow analysis," The Appraisal Journal, vol. 68, pp. 86-92.

Myers, S.C. (1974). "Interactions of corporate financing and investment decisions - implications for capital budgeting," Journal of Finance, vol 29, pp. 1-25.

Mollart, R.G. (1988). "Monte Carlo simulations using Lotus 123," Journal of Property Valuation, vol. 6, pp. 419-33.

Pyhhr, S.A. (1973). "A computer simulation model to measure risk in real estate investment," Journal of the American Real Estate and Urban Economics Association, vol. 1, pp. 48-78.

Wofford, L.E. (1978). "A simulation approach to the appraisal of income producing real estate," Journal of the American Real Estate and Urban Economics, vol. 6, pp. 370-94. 


\section{Appendix 1}

In Figure A.1, we simulate trajectories for 15 years of a market rental values index $\frac{d I_{t, j}^{M R V_{j}}}{I_{t, j}^{M R V_{j}}}=0.04 d t+0.08 d W_{t}^{I_{t, j}^{M R V_{j}}}$ and of a price process $\frac{d P_{t}}{P_{t}}=0.02 d t+0.10 d W_{t}^{P}$ together linked by a correlation $\rho_{P / I_{t, j}^{M R V_{j}}}$. The Figure A.1.(a) presents two trajectories in the case the correlation is not taken into account: we notice a strong difference in the trajectories. On the contrary, the Figure A.1.(b) and A.1.(c) show how the correlation factor influences the paths.

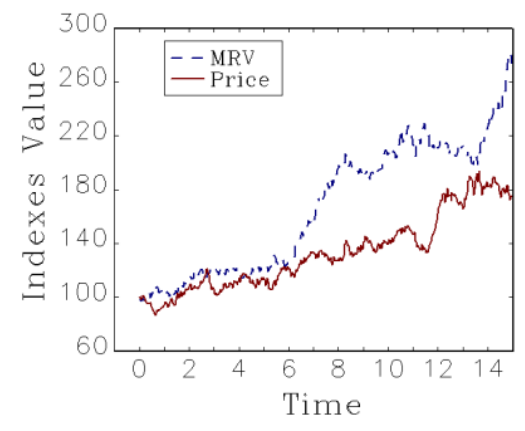

$\rho_{P / I_{t, j}^{M R V_{j}}}=0$

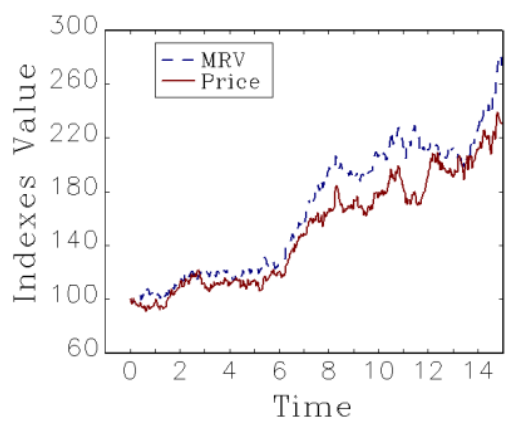

$\rho_{P / I_{t, j}^{M R V_{j}}}=0.6$

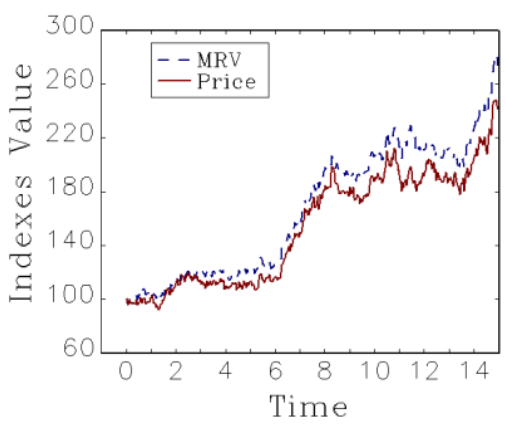

$\rho_{P / I_{t, j}^{M R V_{j}}}=0.9$

Figure A.1. Illustration of the paths' behaviour when correlation is taken into account

\section{Appendix 2}

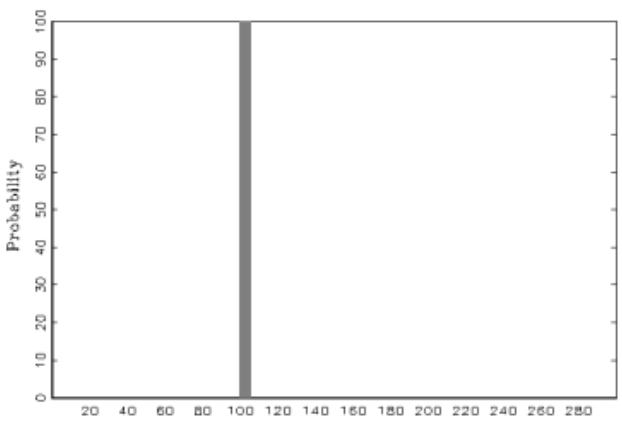

(a) - Histogram of the rents after period 1

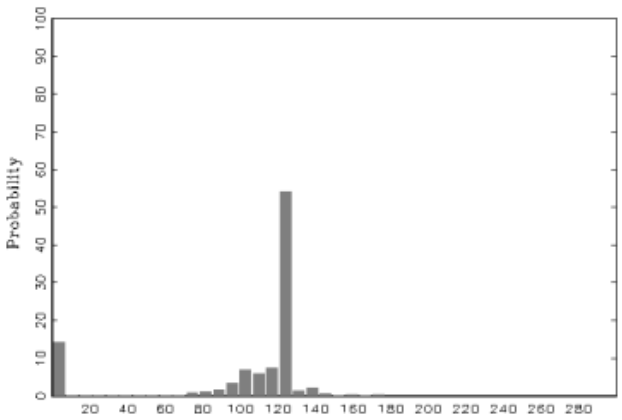

(c) - Histogram of the rents after period 8

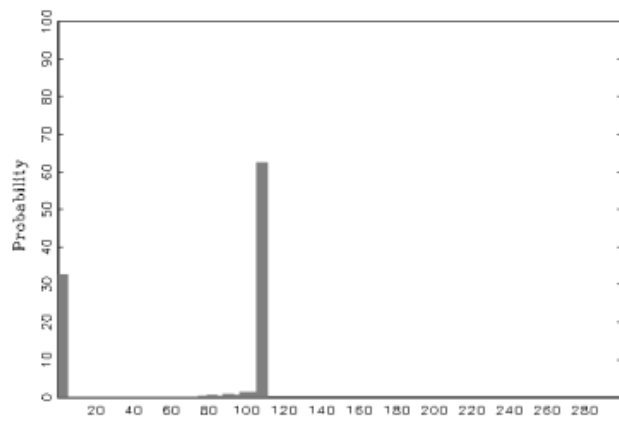

(b) - Histogram of the rents after period 4

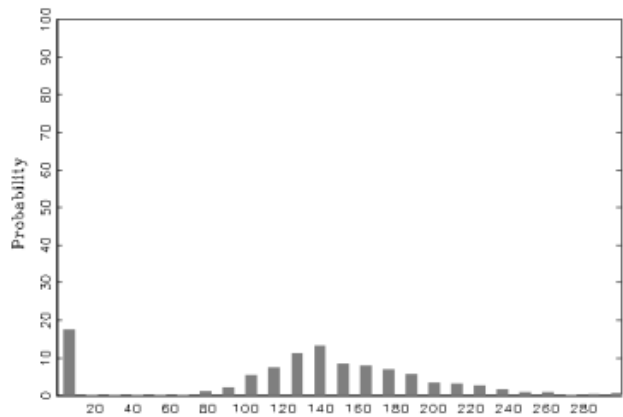

(d) - Histogram of the rents after period 14

Figure A.2. Histogram of the rents of a French lease contract for $t=1, \ldots, 15$. 
Important note: in the histograms rents are not discounted; therefore the values considered on the abscissas do not have to be compared between them. However the distribution of values remains relevant.

Figure A.2 shows the transformation of the distribution throughout a traditional French lease contract. It illustrates the importance of taking the break option into account. Indeed, these options have a major impact on the distribution of possible values that the rent can take.

(a) - Until period 3, all the rents produced are equal; therefore the distribution is concentrated on one point;

(b) - After the first break option - period 4 - the values are mainly concentrated on two points, including point 0 for all the premises that are vacant after the exercise of the first break option and $107.6=100 \times(1+2.5 \%)^{3}$ when the tenants stay in the property. Some other points appear in the distribution and can be attributed to the scenarios when the premises immediately find a new tenant. Thus the transformation is visible after year 3 (at year 4). At this point, a significant part of the rents equals 0 . It represents the simulated state of the market when the space became vacant. This highlights to which extent vacancy influences the distribution of the cash flows. During the two following periods, no break options can be exercised.

(c) - This point occurs after the second break-option. We observe an increase in the number of vacant spaces, which demonstrates that some tenants have exercised their option. This period also exhibits the break options of tenants who have contracted a lease after the departure of the first tenants. However, because of the small number of the tenants involved this fact is not obvious.

(d) - The distribution is completely distorted after the end of the lease (year 9) when the landlord can negotiate a rent equal to the market rental value. Indeed after year 9 all states of the market are possible, because the landlord and the tenant are supposed - under our assumption of rational behavior - to conclude a contract at market value.

\section{Appendix 3}

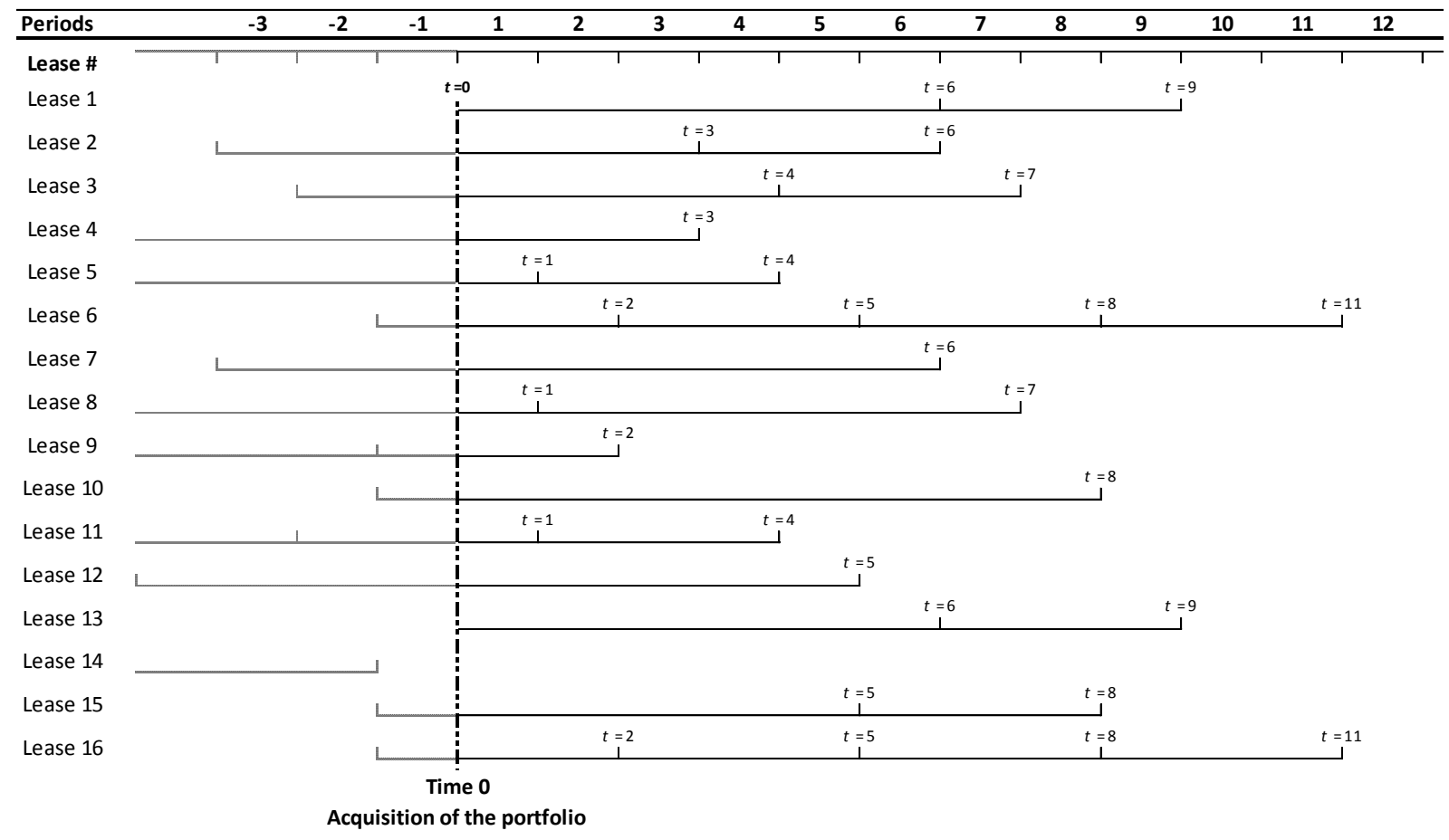

Figure A.3. Leases during the holding period of the portfolio

\section{Appendix 4}




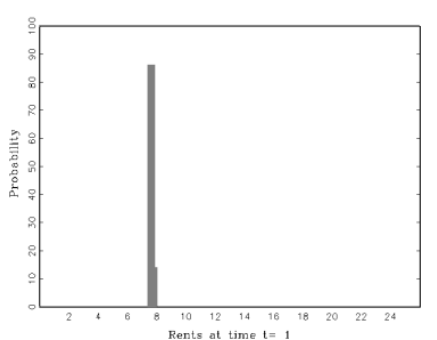

(a)

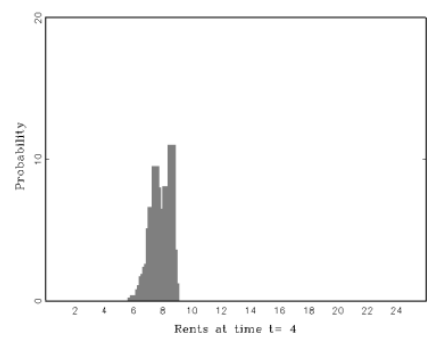

(d)

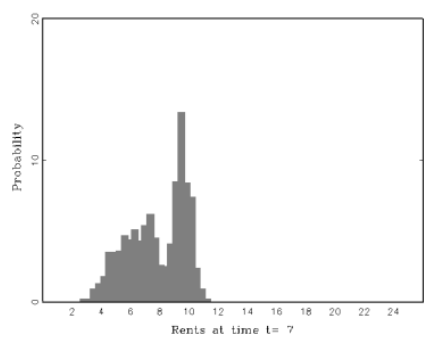

(g)

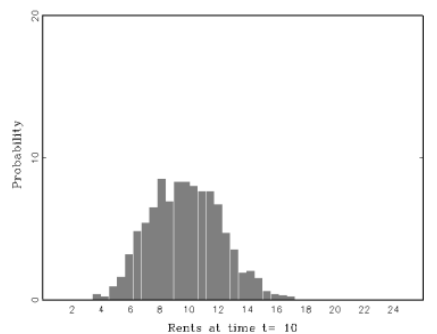

(j)

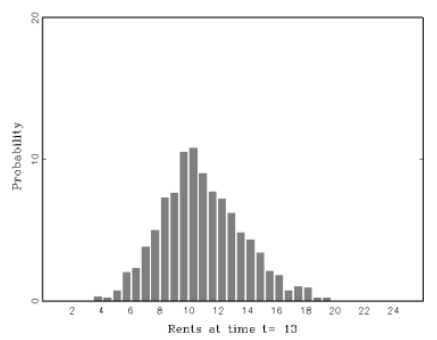

(m)

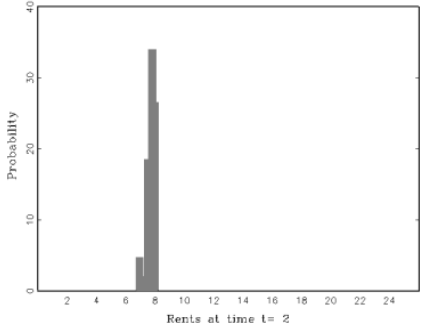

(b)

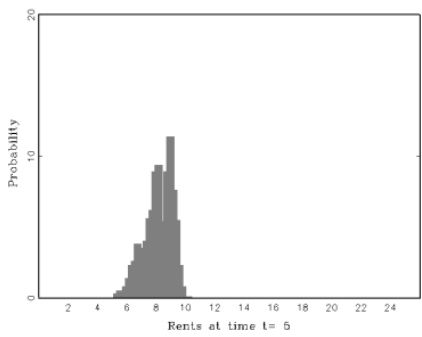

(e)

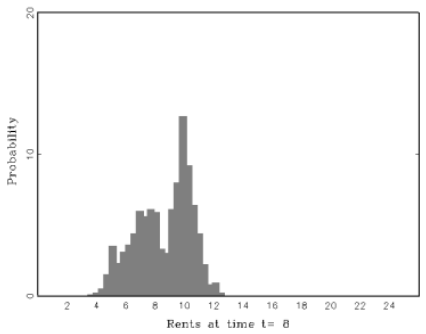

(h)

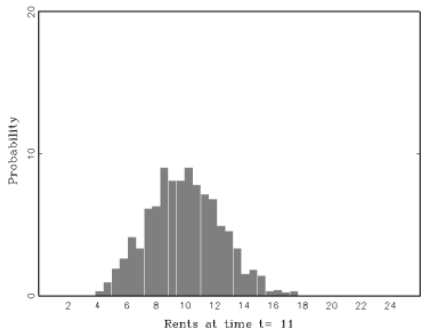

(k)

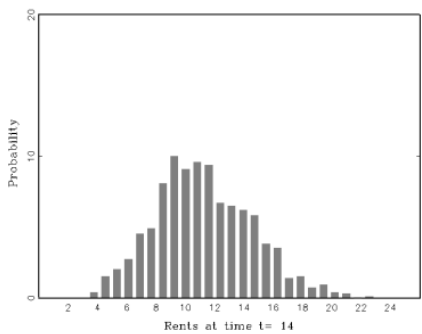

(n)

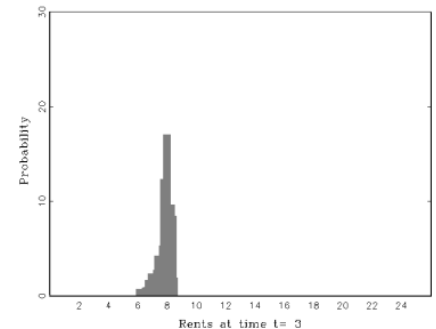

(c)

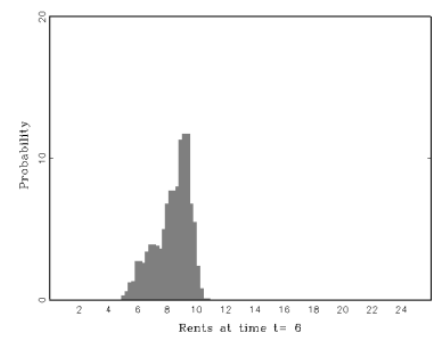

(f)

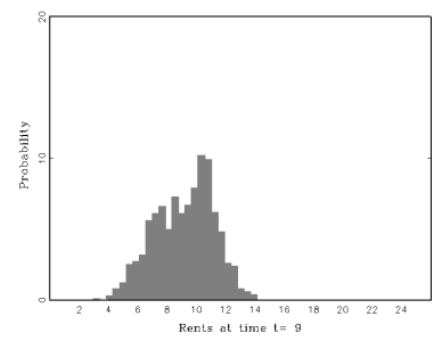

(i)

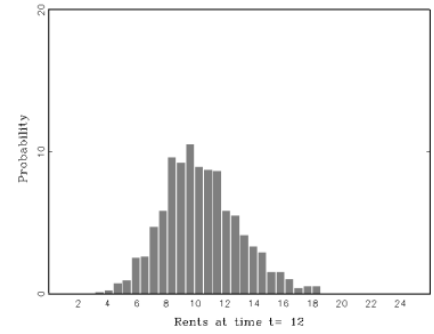

(1)

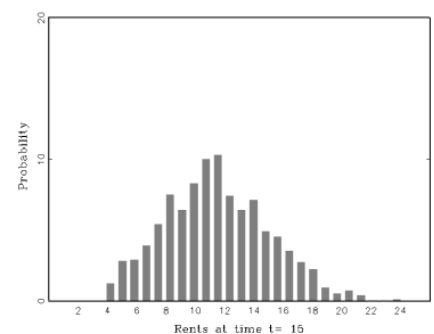

(o)

Figure A.4. Histogram of the possible rents produced by the portfolio for each year during 15 years.

Comments to figure A.4:

(a) - Just after the first period differences appear. This is due to the vacant space that can be let, or not, during the first period.

(g) - The distribution of the rents produced at year 7 is particularly noticeable and shows that this year is especially "risky" for the portfolio. This can be translated into action for portfolio management. For instance, knowing the risk, the decision could be to secure the cash flows of this year either by buying portfolio insurance or by renegotiating the lease contracts in advance, selling one "risky" asset, buying another one to mitigate the risk is the same year. The letting and vacancy risk are therefore valued. 
(o) - The distribution of possible rents is spread and the possibilities are multiple. It can be noticed that it is possible to compute the probability of loss in rental level or the probability of rents falling below a certain amount.

\footnotetext{
i A clear and developed description of the traditional DCF methodology in the light of a comparison with the stochastic model is reported by Baroni, Barthelemy and Mokrane (2007a).
}

ii It is possible to find an analogy in classical financial derivatives. The break option works as a valuable European option. In finance, a European option is a contract between a buyer and a seller that gives the buyer the right, but not the obligation, to buy or sell a particular underlying asset at a later predefined date at an agreed price. In return for granting the option, the seller collects a premium from the buyer. In a capital market, a rational player will exercise a European option at maturity as soon as it terminates if the sum of money, i.e. if its underlying price, is above a predefined point.

By analogy, at the time of a break option, the tenant has the right, but not the obligation, to terminate the lease. A rational tenant will thus terminate the lease only if its option to leave - its break option - is in the money, i.e. only if the market rental value is below the rent paid. However, in contrast with traditional financial analysis, we do not value the premium of the option. Therefore, in our model, the tenant is tempted to leave as soon as the market rental value for available identical space is much less than the current rent.

Note: A Call option is in the money if its underlying price is above a predefined price: $S_{t}>K$, in this case a rational player will exercise the call in order to buy the underlying asset at cheaper price. A Call option is at the money if the price of the underlying asset it is written on, equal the strike price: $S_{t}=K$. A Call option is out of the money if its underlying price is below a predefined price: $S_{t}<K$.

iii Comments on Figure 5:

The cases represented in Figure 5 form a panel of all the cases generated by the simulation.

(a) - None of the break options are exercised by the first tenant during the course of its lease until period 9. However the space is vacated when the lease terminates. But the landlord does not face any vacancy because a new tenant enters the space immediately, so there is no void period. After three years in the premises, the second tenant leaves the space and, once more, a tenant immediately enters the premises without void;

(b) - At the end of year 3, the tenant is able to find a place cheaper than the one it is letting. Therefore, the space is vacated. The vacancy lasts 4 years until the 8 th period when a new tenant is found;

(c) - The first tenant stays in the property until the end of its contract and leave after nine years. At this time, a new tenant enters the space for a higher rent and leaves the property after three years as the market rental value has then fallen. The space remains then vacant until the end of the simulation;

(d) - The first tenant leaves the property at its first break option. The space remains vacant during 5 years. After 3 years in the premises, the second tenant decides to leave and the space has two years of void before a third tenant enters the property.

(e) - The first tenant stays 6 years in the property. After one year of vacancy, the space is let by a second tenant. Three years later the second tenant leaves and the space is vacant for 4 years.

(f) - The property is vacant at the beginning of the simulation. It remains vacant three years. The first tenant enters the property at period 4 and stays six years. The space remains vacant for two years and a second tenant let the space and leaves after three years in the property. 
ESSEC Business School Avenue Bernard Hirsch BP 50105

95021 Cergy-Pontoise Cedex France

Tél. +33(0)134433000

$\mathrm{Fax}+33(0) 134433001$

www.essec.fr

\section{ESSEC Executive Education}

CNIT BP 230

92053 Paris-La Défense

France

Tél. +33(0)146924900

Fax +33(0)1 46924990

http:l/formation.essec.fr

ESSEC Business School

Singapore Campus

100 Victoria Street

National Library Building \# 13-02

Singapore 188064

essecasia@essec.fr

Tél. +6568849780

Fax +6568849781

www.essec.edu

\section{Informations}

Alison Bougi

+33 (0)134433358

bougi@essec.edu

unw.essec.fr

research.center@essec.fr

ISSN 1291-9616 